\title{
Effects of Music in Exercise and Sport: A Meta-Analytic Review
}

\author{
Peter C. Terry \\ University of Southern Queensland \\ Michelle L. Curran \\ University of Southern Queensland
}

\author{
Costas I. Karageorghis \\ Brunel University London
}

Olwenn V. Martin

Brunel University London

\author{
Renée L. Parsons-Smith \\ University of Southern Queensland and University of the Sunshine Coast
}

\begin{abstract}
Regular physical activity has multifarious benefits for physical and mental health, and music has been found to exert positive effects on physical activity. Summative literature reviews and conceptual models have hypothesized potential benefits and salient mechanisms associated with music listening in exercise and sport contexts, although no large-scale objective summary of the literature has been conducted. A multilevel meta-analysis of 139 studies was used to quantify the effects of music listening in exercise and sport domains. In total, 598 effect sizes from four categories of potential benefits (i.e., psychological responses, physiological responses, psychophysical responses, and performance outcomes) were calculated based on 3,599 participants. Music was associated with significant beneficial effects on affective valence $(g=0.48$, CI $[0.39,0.56])$, physical performance $(g=0.31$, CI $[0.25,0.36])$, perceived exertion $(g=0.22$, CI $[0.14,0.30])$, and oxygen consumption $(g=0.15$, CI $[0.02,0.27])$. No significant benefit of music was found for heart rate $(g=0.07$, CI $[-0.03,0.16])$. Performance effects were moderated by study domain (exercise $>$ sport) and music tempo (fast $>$ slow-to-medium). Overall, results supported the use of music listening across a range of physical activities to promote more positive affective valence, enhance physical performance (i.e., ergogenic effect), reduce perceived exertion, and improve physiological efficiency.
\end{abstract}

\section{Public Significance Statement}

This meta-analytic investigation suggests that listening to music before or during physical activity offers potential benefits for exercisers and athletes. Music has the capacity to enhance enjoyment, improve physical performance, reduce perceived exertion, and benefit physiological efficiency across a range of physical activities, albeit the magnitude of the effects tends to be small.

Keywords: affect, asynchronous, mechanisms, moderation, synchronous

Supplemental materials: http://dx.doi.org/10.1037/bul0000216.supp

Music has been a fundamental aspect of human culture and evolution that may even predate verbal communication (Mithen, 2005; Patel, 2008). In various guises, it infuses every society on earth, from the most primitive to the most advanced. Music punctuates our daily lives and accompanies a broad range of activity: it is integral to initiation ceremonies, weddings, and funerals; mothers use it instinctively to offer comfort to a restless child; it rouses soldiers preparing to enter the fray and serves to coordinate their onward march; our most intimate moments are heightened by its presence; and it pervades many aspects of exercise and sport
This article was published Online First December 5, 2019.

(D) Peter C. Terry, Division of Research and Innovation, University of Southern Queensland; (D) Costas I. Karageorghis, Department of Life Sciences, Brunel University London; (D) Michelle L. Curran, School of Psychology and Counselling, University of Southern Queensland; (D) Olwenn V. Martin, Institute for the Environment, Health and Societies, Brunel University London; (D) Renée L. Parsons-Smith, School of Psychology and Counselling, University of Southern Queensland, and School of Social Sciences, University of the Sunshine Coast.
No monetary or in-kind funding support was provided during the conduct of this synthesis, other than time allocated to the task by the authors' respective universities. There are no potential financial or nonfinancial conflicts of interest. The contribution of the following people in the earlier stages of this meta-analytic investigation is duly acknowledged: Julian Lim, Alessandra Mecozzi Saha, Janine Lurie, Rhonda Stanton, and Shahjahan Khan.

Correspondence concerning this article should be addressed to Peter C. Terry, Division of Research and Innovation, University of Southern Queensland, Toowoomba, QLD 4350, Australia. E-mail: peter.terry@usq.edu.au 
(Clark, Baker, \& Taylor, 2016; Levitin, 2006). Indeed, so fundamental is music to the human condition that German philosopher Friedrich Nietzsche famously declared, "Without music, life would be a mistake."

A sharp increase in obesity, physical inactivity, and cardiorespiratory diseases is a source of growing concern to governments and national health providers in many developed nations (Radford et al., 2018; Wanner, Richard, Martin, Faeh, \& Rohrmann, 2017). Lack of physical activity is one of the principal risk factors for noncommunicable diseases, which are the leading cause of death globally. A well-documented barrier to continued engagement in physical activity concerns the lack of pleasure derived from participation (e.g., Williams, Dunsiger, Jennings, \& Marcus, 2012). Accordingly, in recent years, the field of exercise and health psychology has witnessed a paradigmatic shift from cognitivism toward hedonism (Ekkekakis, Hartman, \& Ladwig, 2020). The upshot of this shift in practical terms, is that messages highlighting rational reasons for physical activity participation (i.e., "it's really good for you") should be supplemented by an emphasis on experiences that are pleasant and enjoyable (Brand \& Ekkekakis, 2018).

Reaping the benefits of physical activity is entirely contingent upon habitual and frequent engagement. For this reason, the psychological components that underlie physical activity adherence have come into sharp focus (Ekkekakis et al., 2020). Of these, the construct of affect, a gestalt assessment of how pleasant and aroused one feels, is paramount. Earlier work showing the importance of experiencing positively valenced affect to reinforce physical activity behavior has given way to more nuanced explanations. For example, Parfitt and Hughes (2009) elucidated the implications of the peak-end rule, which holds that instances of extremely positive affective experience (referred to as affective peaks) during physical activity, and especially during its final moments, encourage future participation via the proposed mechanism of affective memory (Fredrickson \& Kahneman, 1993).

Physical activity intensity is thought to be a key determinant of affect and is duly considered as a moderating variable in the present analysis. The dual-mode theory proposed by Ekkekakis (2003) provides a framework describing the affective impact of three levels of physical activity intensity that vary qualitatively. Moderate physical activity, which is lower than the ventilatory threshold (i.e., the intensity at which breathing becomes labored), is characteristically pleasurable. Heavy physical activity, which lies close to the ventilatory threshold, may be perceived as pleasurable or displeasurable depending on the interpretation of the performer. Severe physical activity, which lies beyond the ventilatory threshold, is almost universally perceived as displeasurable.

Given its propensity to enhance affective states during physical activity, music has been advocated as a means by which to increase adherence to physical activity (e.g., Clark et al., 2016; Hutchinson et al., 2018). The role of music may prove especially beneficial, given that it has been shown to have a positive influence on affective valence, even at higher physical activity intensities (e.g., Bigliassi, Karageorghis, Nowicky, Orgs, \& Wright, 2016; Terry, Karageorghis, Mecozzi Saha, \& D’Auria, 2012). Accordingly, music may help to counter the negatively valenced affect that is typically associated with severe physical activity, or alter the interpretations of heavy physical activity toward the positive. From a behavioral change perspective, music may build associations between physical activity and positively valenced affect that influence future decision-making processes (Williams et al., 2012).

\section{The Role of Music in Physical Activity}

In developed countries, wherein the majority of the population is not engaged in manual labor, a lack of enjoyment is frequently cited as a barrier to participation in physical activity (e.g., Burgess, Hassmén, \& Pumpa, 2017). The ubiquitous and culturally dominant force of music in the realm of physical activity has been explained in terms of its capacity to promote improved feeling states and enjoyment (e.g., Hallett \& Lamont, 2017; Hutchinson et al., 2018). The affective qualities of music have led researchers to suggest that it has a role to play in enhancing physical activity compliance and outcomes among apparently healthy participants, as well as those undertaking remedial physical activity as part of a rehabilitation program (e.g., Annesi, 2001; Clark, Baker, Peiris, Shoebridge, \& Taylor, 2017).

The term physical activity covers a broad array of behaviors that share a physical component but are otherwise quite disparate. Such behaviors range from engagement in highly codified activities in the sports domain, structured exercise, or dance classes, through to less formal physical activities such as walking, housework, gardening, and manual labor. We have delimited the present investigation to two specific areas of physical activity; namely, exercise and sport. We included walking for exercise in the investigation, but we excluded investigations into the effects of music on gardening, housework, and manual labor; first because such studies are relatively sparse, and second, because they do not fall within the primary domains of interest. Study domain (i.e., exercise vs. sport) is important from an empirical perspective, given that with typically less coaction/interaction coupled with less complex kinematics in the exercise domain, it might be expected that the effects of music would be stronger here than in the sport domain (i.e., with less error variance and fewer degrees of freedom, the effects are more readily detected). Accordingly, study domain is included as a potential moderator in our meta-analysis.

In light of the fact that dance is a common form of physical activity and inextricably linked with music, we gave consideration to the inclusion of dance-related studies. There are, however, at least two compelling reasons for the noninclusion of the large body of dance-related studies in the present analysis. First, summative reviews of the benefits of dance therapy have already been published (e.g., Dos Santos Delabary, Komeroski, Monteiro, Costa, \& Haas, 2018). Second, our focus is on categories of physical activity in which the experience might be enhanced (e.g., in terms of performance levels or psychological responses) by the presence of music through augmenting any benefits that would be inherent to the activity. We have therefore excluded physical activities in which music plays an integral part, such as dance, ice skating, and rhythmic gymnastics. Such activities entail a physical interpretation of a musical composition and given that music is at their core, it is a considerable challenge to disaggregate the influence of music on the response of the human organism per se.

\section{Proposed Benefits of Music in Exercise and Sport}

Investigations into the benefits of music during exercise- and sport-related activities have a long history, dating back at least to 
Ayres (1911) who observed that competitors in a 6-day cycle race traveled $8.5 \%$ faster when a military band was playing. Since then, music has been shown to be associated with improved physical performance in a broad range of activities (see Karageorghis, 2020 for a review).

Evidence indicates that music elicits several interrelated benefits in the context of exercise- and sport-related tasks. For example, pretask music has been used successfully as a stimulant (e.g., Eliakim, Meckel, Nemet, \& Eliakim, 2007) or as a relaxant (e.g., Karageorghis, Bigliassi, Tayara, Priest, \& Bird, 2018). When used during physical activity, music can elicit positive affective states (e.g., Hutchinson et al., 2018) and distract exercisers or athletes from the unpleasant sensations associated with physical effort and fatigue (e.g., Hutchinson \& Karageorghis, 2013). These benefits may contribute to the ergogenic effects identified in empirical studies. Such effects include heightened strength and power output (e.g., Hutchinson et al., 2011; Karageorghis, Cheek, Simpson, \& Bigliassi, 2018), increased endurance (e.g., Atkinson, Wilson, \& Eubank, 2004; Terry, Karageorghis, et al., 2012), and improved work rate (e.g., Edworthy \& Waring, 2006; Lee \& Kimmerly, 2016). Ergogenic effects have been reported both when participants have synchronized their movements with music (Karageorghis et al., 2009, 2010; Terry, Karageorghis, et al., 2012) and in the absence of synchronization (Hutchinson et al., 2018; Stork, Kwan, Gibala, \& Martin Ginis, 2015). The mode of music delivery (i.e., pretask vs. synchronous vs. asynchronous) is of considerable empirical and theoretical interest; accordingly mode is included as a moderator variable in the present study.

The role of music in aiding recovery after physical activity is relatively unexplored, although the literature on this subject has expanded recently (e.g., Jia, Ogawa, Miura, Ito, \& Kohzuki, 2016; Karageorghis, Bruce, et al., 2018). The efficacy of relaxing music in providing recuperative effects following moderate-intensity and high-intensity physical activity has been demonstrated in several studies (e.g., Jing \& Xudong, 2008). The capacity of music to induce a range of physiological changes, involving respiration, heart rate, skin conductance, motor patterns, neuroendocrine response, and immunological function, has been supported empirically (e.g., Ooishi, Mukai, Watanabe, Kawato, \& Kashino, 2017). Similar physiological effects of music have also been observed during physical activity (e.g., Jones, Tiller, \& Karageorghis, 2017).
Karageorghis and colleagues have published several conceptual models that represent how various effects of music occur in physical activity contexts (Bishop, Karageorghis, \& Loizou, 2007; Karageorghis, 2016; Karageorghis, Bigliassi, et al., 2018; Karageorghis, Terry, \& Lane, 1999; Terry \& Karageorghis, 2006). There is also a metatheory offered by Clark et al. (2016) that represents the contexts of therapeutic outcomes, sport and exercise performance, and auditory-motor processing. For the purposes of the present meta-analysis, we used the model shown in Figure 1 to inform our objective summary of the extant literature. This adapted model provides a parsimonious representation of the relevant antecedents, intermediaries, benefits, and outcomes in the musicphysical activity nexus. The hypothesized benefits of music are separated into the four categories of psychological responses, psychophysical responses, physiological responses, and enhanced physical performance. These categories provided a guiding framework for the present meta-analysis.

Within the model, properties specific to the musical stimulus itself are grouped into four categories: rhythm response, musicality, cultural impact, and associations (see Karageorghis et al., 1999). Rhythm response relates to natural responses to musical rhythm, especially tempo (speed of music as measured in beats per minute). Musicality refers to pitch-related elements such as harmony (how the notes are combined) and melody (the tune). Cultural impact is the pervasiveness of the music within society or a subcultural group. Association pertains to the extramusical associations that music may evoke, such as the composition Chariots of Fire by Vangelis, with Olympic glory. Given that rhythm response and musicality relate to audible properties of the musical stimulus, they constitute internal factors whereas cultural impact and association constitute external factors.

In the world of sport, athletes may use music to relax, to feel stimulated, or to generate a particular precompetition mindset (Karageorghis, Biglassi, et al., 2018; Laukka \& Quick, 2013). Organizers of sporting events use music to create an atmosphere of excitement, patriotism, or tension among crowds of spectators (Steinbach, 2008; Tubino, de Souza, \& Valladão, 2009). It is apparent that many people intuitively believe that music has potential benefits in the physical activity domain, although compelling evidence of such benefits has yet to be summarized objectively. The specific effects of music in physical activity contexts

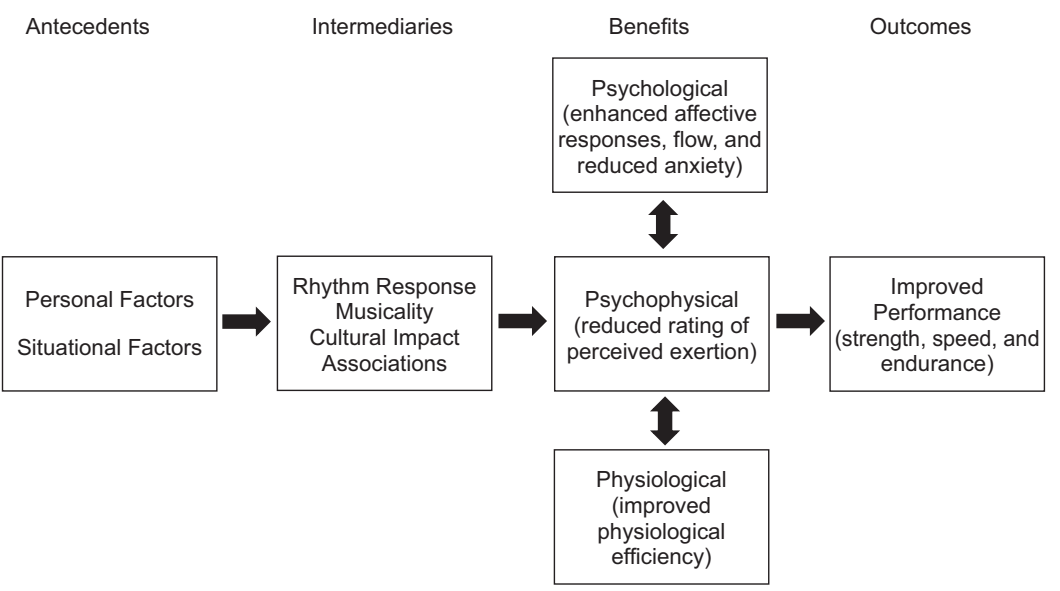

Figure 1. Conceptual framework for the benefits of music in exercise and sport. 
are dependent upon a wide range of musical, personal, and situational variables. Such variables include, but are not limited to, age and gender (Clark, Taylor, \& Baker, 2012; Karageorghis et al., 2010), music familiarity (Elvers \& Steffens, 2017; Pereira et al., 2011), music preference (Crust, 2008; Hutchinson et al., 2018), music tempo (Karageorghis, Jones, et al., 2011; Van Dyck et al., 2015), physical activity intensity (Hutchinson \& Karageorghis, 2013; Tenenbaum et al., 2004), participant training status (Brownley, McMurray, \& Hackney, 1995; Carlier \& Delevoye-Turrell, 2017), and the specific nature of the physical activity (Karageorghis et al., 2009; Simpson \& Karageorghis, 2006).

Several variables are explored in the present study by use of moderator analyses, given their theoretical and empirical relevance. Specifically, music preference is examined by coding for researcher-selected or self-selected music. Music tempo is examined by coding for tempo $\geq 120 \mathrm{bpm}$ and $<120 \mathrm{bpm}$. Notably, 120 bpm is a crucial cutoff point from the contrasting perspectives of musical aesthetics (MacDougall \& Moore, 2005), human locomotion (Hirasaki, Moore, Raphan, \& Cohen, 1999), and neurophysiology (Schneider, Askew, Abel, \& Strüder, 2010).

Physical activity intensity is examined using $70 \%$ of aerobic capacity $\left(\dot{\mathrm{VO}}_{2} \max \right)$ as the cutoff point, with low-to-moderate activity classified below this intensity level and high-intensity activity at or above this level. This cutoff point is widely considered to be indicative of the beginning of the shift from aerobic metabolism (i.e., in the presence of oxygen) to anaerobic metabolism (i.e., in the absence of oxygen), although this metabolic shift may vary in accord with an individual's level of cardiorespiratory fitness (Radák, 2018). Participant training status is examined by coding the activity level of participants, using engagement in regular physical activity ( $\geq 3$ times/wk) as the cutoff between trained and untrained. Training status is worthy of investigation given the potential of music to provide an extrinsic source of motivation and an easy form of dissociation, for those who struggle to meet minimal physical activity guidelines (e.g., Clark et al., 2016).

Mode of music delivery is examined by coding effects on the basis of whether they relate to the pretask, asynchronous, or synchronous applications of music, in accord with the definitions provided by Karageorghis (2020). Synchronous applications are not split into active (i.e., conscious synchronization of movement rate with music) and passive (i.e., technology-mediated adaptation of music tempo in real-time) categories, as recently suggested by Karageorghis, due to a paucity of data for the latter.

Study quality is a potential moderator (i.e., low vs. medium quality), as poorly controlled studies might restrict the identification of music-related effects. Study design is also a potential moderator, given that within-subjects studies, which are less susceptible to between-subjects error (Tabachnick \& Fidell, 2018), are more likely to reveal the true effects of music. Finally, study location (laboratory vs. field) and domain (exercise vs. sport) are coded in preparation for moderator analyses, given that effects of music in field settings are likely to be smaller or more diffuse due to other stimuli that might bear influence on participants. Similarly, the benefits are likely to be smaller or more diffuse in a sport context given the complexities of movement involved and the degree of human interaction. Exercise tasks are generally better standardized in terms of movement pattern and intensity than sport-related tasks (see Karageorghis \& Priest, 2012a, 2012b for a review).

\section{Mechanisms Underlying the Effects of Music}

The past two decades have witnessed a steady stream of scholarly works that shed light on the mechanisms underlying the effects of music in exercise and sport (e.g., Bigliassi et al., 2016; Grahn \& Brett, 2007). This subsection is organized to briefly address a typology of three salient mechanisms. First, we consider the use of music in regulating or modulating affective and emotional states. Second, we examine music as a distractive tool with reference to attentional frameworks. Third, we consider rhythmic responses to music with a focus on the principle of auditory-motor synchronization and neural correlates of rhythmic action.

\section{Music, Affect, and Emotions}

One of the most frequently cited uses of music by exercisers and athletes involves the control of psychomotor arousal, the regulation or modulation of affective states, and the inducement of specific emotions (e.g., happiness, liveliness, calmness, or aggression). In the present context, we use the term affect to refer to a neurophysiological state that is consciously accessible as a simple primitive nonreflective feeling (Russell \& Barrett, 1999). We use the term emotion with reference to feelings that are typically brief, intense, and attributable to a discernible cause (Beedie, Terry, \& Lane, 2005).

A theoretical framework offered by Juslin (2013) suggests eight psychological mechanisms by which music influences affective and emotional responses. To highlight a few of these, the brain stem reflex, refers to the process by which the fundamental acoustic properties of music stimulate responses by signaling a potentially important or urgent event. For example, fast, loud music would automatically stimulate the listener by activating the central nervous system irrespective of how the music is subsequently appraised (see Van Dyck, 2019 for a review). This stimulation results in elevated heart rate, blood pressure, body temperature, skin conductance, and muscle tension (Chapados \& Levitin, 2008). Soft, slow music has the converse effect and thus decreases sympathetic arousal. Such relaxing music often mimics the soothing sounds that can be found in nature; examples include maternal vocalizations, purring, and cooing (Chanda \& Levitin, 2013).

When high levels of psychomotor arousal are desirable, such as during high-intensity training bouts, the potential of the musical stimulus to arouse becomes of seminal importance (Chanda \& Levitin, 2013). Allied to this is the biomusicological process of rhythmic entrainment. The rate of movement and bodily pulses such as heart rate and respiration rate are drawn toward synchronization with the rhythmical qualities of music. Invariably, people express a preference for tempo to remain relatively high during intense exercise (Thaut, 2008). Along similar lines, given the propensity for brain waves to entrain with musical tempo (e.g., Will \& Berg, 2007), music can have a priming effect preexercise or as part of an athlete's precompetition routine (Loizou \& Karageorghis, 2015).

Scherer and Zentner (2001) highlighted that music may impact upon us by serving as a trigger for emotional associations, a process that may rely on subcortical mechanisms. According to 
appraisal theory, the affective responses to music during physical activity stem from an individual's subjective evaluation of the experience (Scherer, 1999). Somewhat related to this notion, is Juslin's (2013) hypothesized mechanism of evaluative conditioning, which refers to the repeated pairing of a particular piece of music with other positively or negatively valenced stimuli. For example, a specific song may, through repetition, become inextricably linked with a particularly pleasurable physical activity experience. This process represents a form of classical conditioning, wherein a previously neutrally valenced conditioned stimulus (i.e., a piece of music) gains the ability to evoke the same emotional response as a positively valenced unconditioned stimulus (i.e., a pleasurable physical activity experience).

\section{Music, Distraction, and Perceptions of Exertion}

Neural mechanisms that influence perceptions of exertion are thought to underlie some of the effects of music in exercise and sport. The afferent nervous system, which transmits impulses toward the brain and spinal column, exhibits a limited channel capacity (analogous to Internet bandwidth). Consequently, sensory stimuli such as music may inhibit the physiological feedback signals associated with physical exertion (e.g., Rejeski, 1985). Experimental work using electroencephalography has shown that music is effective in reducing theta waves $(4-7 \mathrm{~Hz})$ in the frontal, central, parietal, and occipital regions of the brain (Bigliassi et al., 2016). This process has been directly associated with the suppression of fatigue-related symptoms (see Craig, Tran, Wijesuriya, \& Nguyen, 2012).

The inhibitory capacity of music may be reduced at higher physical activity intensities when the signal strength of physiological feedback is more potent (Ekkekakis, 2003; Tenenbaum, 2001); a phenomenon that will be subject to examination via moderator analyses in the present study. Nonetheless, even during highintensity physical activity, affective stimuli such as music retain an influence on how we feel and therefore how we interpret the sensations of physical effort and fatigue (Bigliassi et al., 2016; Hutchinson \& Karageorghis, 2013). In other neurophysiological work using electroencephalography, it was demonstrated that music reduced brain connectivity across frontal and central regions of the cortex (i.e., the sensorimotor regions); a phenomenon that is associated with reduced exercise consciousness (Bigliassi, Karageorghis, Wright, Orgs, \& Nowicky, 2017).

\section{Rhythmic Responses to Music}

From an evolutionary perspective, it seems that humans have developed a genetic predisposition to respond to music (Patel, 2008; Phillips-Silver \& Keller, 2012). The human tendency to respond physiologically to music and synchronize movement to musical rhythms is important in helping to explain the potential benefits of music in the realm of exercise and sport. The coupling of perception and movement is guided by recurrent patterns in the structure of music (Leman et al., 2013). Coupling pertains to the connection between agents that enables them to communicate and receive information about each other's actions (Himberg, 2017). In the case of entrainment, coupling is normally mutual or bidirectional, allowing two agents to perceive and influence each other. In the application of sychronous music, until recently, the coupling was unidirectional, as the exerciser or athlete could follow the musical rhythm, but the rhythm did not change in response to her or his movement rate. Exercisers can now use accelerometers and digital interfaces that facilitate mutual synchronization (e.g., DJogger; Moens et al., 2014). The central processing demands in the case of mutual synchronization (i.e., music that adjusts in real-time to fit an individual's movement rate) are, conceivably, of a lesser order when compared with unidirectional coupling, albeit comparative studies of this nature have yet to emerge.

It has been proposed that a central pattern generator or pacemaker in the brain may serve to regulate temporal functioning and govern the rhythm response- the innate human predisposition to synchronize movement with musical rhythms (Schneider et al., 2010). This mechanism would coordinate afferent nerve signals with their efferent counterparts that control movement and also regulate locomotion, neurovascular control, and sensory integration.

The process of synchronizing movement with music, often referred to as auditory-motor synchronization (Bood, Nijssen, van der Kamp, \& Roerdink, 2013; Schmidt-Kassow, Heinemann, Abel, \& Kaiser, 2013), is a form of rhythmic entrainment (see Juslin, 2013). In mechanistic terms, exercising in synchrony with music may lower the metabolic cost of the activity by promoting greater neuromuscular and kinetic efficiency (Bacon, Myers, \& Karageorghis, 2012; Terry, Karageorghis, et al., 2012). Moderator analyses in the present study will duly address the efficacy of auditory-motor synchronization in the exercise and sport context. Field-based work involving a walking task found that, regardless of tempo, the activating or relaxing qualities of music influence movement rate (Leman et al., 2013). Thus, the sonic energy in terms of loudness, pitch, and rhythmic accentuation (i.e., how beats are grouped into patterns) has a bearing on the degree of auditory-motor synchronization.

Such field-based work brings into focus the importance of study location in this domain of scientific research. Although wellcontrolled, laboratory-based studies can be configured to limit the effects of potential confounds and standardize many aspects of the environment (e.g., Hutchinson et al., 2018; Stork, Karageorghis, \& Martin Ginis, 2019), the lack of ecological validity means that aspects of human responsivity to music can be either lost or obfuscated. Accordingly, in the present investigation, study location (i.e., laboratory vs. field) is assessed as a potential moderating variable.

\section{Rationale and Purpose of the Present Study}

The effects of music have been subject to investigation in many contexts, resulting in several systematic and meta-analytic reviews (e.g., coronary heart disease-Bradt \& Dileo, 2009; cancerZhang et al., 2012). Such reviews have been based on a relatively small number of studies (range $=19-32$ ). By comparison, the number of studies conducted in the realm of exercise and sport is far more extensive. Although several narrative reviews (e.g., Karageorghis \& Priest, 2012a, 2012b; Smirmaul, 2017) have been produced, no comprehensive quantitative summary of the effects of music in exercise and sport domains has yet been published. Two meta-analytic reviews (Clark et al., 2012; Kämpfe, Sedlmeier, \& Renkewitz, 2011) and two narrative reviews (Van Dyck, 2019; Ziv \& Lidor, 2011) have addressed research questions 
related to the present investigation but none has provided a comprehensive summary of the central research questions of interest. For example, Clark et al. (2012) focused on the effectiveness of music interventions in increasing physical activity specifically among older adults, and included just 12 studies; Kämpfe et al. (2011) conducted a more general meta-analysis of the impact of background music on adult listeners, which included a very limited coverage of physical activity-related studies; and Ziv and Lidor (2011) reviewed 20 studies investigating effects of adding music to exercise programs among clinical populations and the elderly.

A key characteristic of the literature on which the present study is predicated is the great variety across studies in terms of the musical stimuli used, the tasks employed, the type of participants, and the putative effects being tested. As noted in an early review (Karageorghis \& Terry, 1997), music and physical activity-related studies have tended to produce equivocal findings, not least because of the difficulty in drawing equitable comparisons. Thus, the very nature of the subject area makes a coherent, objective summary entirely necessary.

The purpose of the present meta-analysis was to quantify the effects of music in exercise and sport domains. Effects expressed in terms of Hedges' $g$ were assessed separately for the four categories of potential benefits identified in Figure 1; namely, psychological responses, physiological responses, psychophysical responses, and performance outcomes.

\section{Outcome Variables}

Under the four categories of potential benefits, there are specific outcome variables that have featured prominently in the literature. First, affective valence, as operationalized by the single-item Feeling Scale (FS; Hardy \& Rejeski, 1989)_-developed specifically as an in-task measure for exercise contexts-is popular among researchers, particularly those operating in laboratory settings (e.g., Hutchinson et al., 2018; Stork et al., 2015). Second, the physiological variables of heart rate $(\mathrm{HR})$ and oxygen uptake $\left(\dot{\mathrm{VO}}_{2}\right)$ are common dependent measures in this area of study, albeit the former is more readily assessed than the latter and hence is used more frequently (e.g., Lim, Karageorghis, Romer, \& Bishop, 2014; Thakare, Mehrotra, \& Singh, 2017). Third, from the earliest years of music-related research, the ability of music to narrow attention and make physical tasks seem less arduous has been well documented (e.g., Anshel \& Marisi, 1978; Ayres, 1911). Accordingly, the psychophysical outcome of rating of perceived exertion (RPE) has been extremely popular and is facilitated by Gunnar Borg's RPE scales (Borg, 1970, 1982, 1998).

Determining whether music-induced decreases in RPE, HR, and $\dot{\mathrm{VO}}_{2}$ represent an advantage or disadvantage is an important and somewhat complex process. In study designs where workload is consistent across conditions (e.g., Dyrlund \& Wininger, 2008; Terry, Karageorghis, et al., 2012), lower RPE, HR, and $\dot{\mathrm{VO}}_{2}$ values represent a benefit of music (i.e., same workload for lower perceived exertion and physiological strain) whereas higher values represent a disadvantage of music (i.e., same workload for higher perceived exertion and physiological strain). In study designs where participants are required to produce maximal workload (e.g., Hutchinson et al., 2011; Stork et al., 2015), to go faster (e.g., Atkinson et al., 2004; Tate, Gennings, Hoffman, Strittmatter, \& Retchin, 2012), or to maintain effort for longer (e.g., Bood et al.,
2013; Copeland \& Franks, 1991), interpretation of any benefit of music is more challenging. If music-induced RPE, HR, and $\mathrm{VO}_{2}$ values are lower despite an equivalent or greater workload having been completed, this clearly represents a benefit of music. Conversely, if music-induced RPE, HR, and $\dot{\mathrm{VO}}_{2}$ values are higher despite an equivalent or lesser workload having been completed, this clearly represents a disadvantage of music. However, where music-induced RPE, HR, and $\dot{\mathrm{VO}}_{2}$ values are higher with a greater workload (e.g., Atkinson et al., 2004; Sanchez, Moss, Twist, \& Karageorghis, 2014), it is unclear whether this is indicative of any advantage or disadvantage. To ameliorate this uncertainty, those effects where increased RPE, HR, and $\dot{\mathrm{VO}}_{2}$ values were associated with greater workload were not included in our analyses.

Finally, the purported ergogenic effects of music are normally assessed by use of objective performance outcomes (time, distance, speed, power, repetitions, etc.) and many types of physical performance have been assessed in experimental studies (e.g., cycling-Atkinson et al., 2004; running-Terry, Karageorghis, et al., 2012; swimming-Tate et al., 2012). We did consider the inclusion of additional outcomes variables (e.g., blood pressure, blood lactate, mood state), but our initial scan of the literature revealed a paucity of relevant studies.

\section{Moderator Variables}

A wide variety of moderating effects were tested in accord with the personal and situational factors identified as antecedents, and music-related factors depicted as intermediaries in Figure 1. These moderator analyses addressed whether music exerts a similar effect in both exercise and sport settings, whether the effects of music are moderated by participant training status (trained vs. untrained), situational variables (exercise vs. sport, laboratorybased vs. field-based studies), and music characteristics (selfselected vs. researcher-selected, fast vs. slow-to-medium tempo, pretask vs. synchronous vs. asynchronous delivery). Heterogeneity of effect sizes for between- and within-subjects study designs was assessed using $Q$-test values.

\section{Method}

\section{Search Procedures}

Consistent with our underlying theoretical model (see Figure 1), search procedures focused on studies investigating whether listening to music provides psychological, psychophysical, physiological, or performance benefits for exercisers or sportspeople, compared with engaging in the same physical activities with no music. A comprehensive literature search was conducted to locate published investigations of effects of music on physical activity from the earliest known publication (Ayres, 1911) up to a cutoff date of December 31, 2017. Articles available as advance online publications in 2017 were considered for inclusion and, where included, the full 2018 referencing details of the published article are provided in our reference list. Only abstracts or articles published in English in scholarly journals were considered.

The systematic nature of the search served to reduce bias potential and increase the probability of locating rogue articles in addition to those from major journals. The search included several phases. Initially, an electronic search was completed during April 
2018 using the following key search terms: "Music" AND "sport" OR "exercise" OR "physical activity". Databases searched were: Academic Search Ultimate; E-Journals; ERIC; Library, Information Science and Technology Abstracts; PsycARTICLES; Psychology and Behavioral Sciences Collection; PsycINFO; ProQuest; PubMed; Science Direct; Scopus; and SPORT Discus. Google Scholar was used to search for additional studies. Following this, reference lists of obtained research studies were manually screened to identify additional relevant studies, and a manual trawl was conducted of 81 relevant journals. Previous summaries of the literature relevant to music in exercise and sport (e.g., Clark et al., 2012; Karageorghis, 1992) were also examined, and the personal web pages of prominent researchers in the area were scrutinized to identify further studies for potential inclusion. Where an electronic copy was unavailable, a physical copy was sourced using the interlibrary loan facility of state universities (DocEx). Where insufficient data were included in an article to enable effect size calculation, attempts were made to contact study author(s). In total, 37 authors were emailed, yielding 14 responses (38\%), allowing 11 additional studies to be considered for inclusion.

\section{Inclusion Criteria}

To be eligible for inclusion in the meta-analysis, studies needed to have (a) been conducted in an exercise or sport setting; (b) used a music intervention; (c) assessed one or more of the outcome variables of interest: FS, RPE, HR, $\dot{\mathrm{V}} \mathrm{O}_{2}$, objective performance; (d) included a no-music control group or condition in the study design; (e) included sufficient statistics to facilitate calculation of effect sizes; (f) been available in the English language; and (g) been published in a peer-reviewed journal prior to the cutoff date.

Additionally, studies were excluded if the effect of a music intervention could not be isolated from, for example, accompanying video footage (e.g., Barwood, Weston, Thelwell, \& Page, 2009; Bigliassi, Peruzollo, et al., 2014), imagery (e.g., Blumenstein, Bar-Eli, \& Tenenbaum, 1995) or visual manipulation (e.g., Razon, Basevitch, Land, Thompson, \& Tenenbaum, 2009), if a case-study design had been used (e.g., Mesagno, Marchant, \& Morris, 2009), if a clinical or special population had been studied (e.g., De Bourdeaudhuij et al., 2002; Goosey-Tolfrey, West, Lenton, \& Tolfrey, 2011), or if subjective measures of performance were used (e.g., Ferguson, Carbonneau, \& Chambliss, 1994).

\section{Unpublished Studies}

There has been rigorous debate in relation to the inclusion or exclusion of unpublished studies in meta-analytic works (e.g., Sterling, Rosenbaum, \& Weinkam, 1995). A central issue concerns publication bias, wherein publication tends to be restricted to studies that report significant results, leaving investigations with nonsignificant results to be consigned to the "file drawer." Rosenthal and DiMatteo (2001) proposed that the omission of unpublished studies can inflate the overall effect size, if publication bias is genuinely present in the literature. On the other hand, support for the exclusion of unpublished studies points to their lack of rigorous peer-review scrutiny (Sterling et al., 1995).

A decision was made to exclude unpublished studies from the present meta-analysis because (a) with a 107-year window for the meta-analysis it was not possible to obtain a representative sample of unpublished work from the period (researchers had passed away, institutions had closed, addresses were no longer valid, etc.), (b) searches through databases such as ProQuest Dissertations and Theses located relatively few unpublished studies of direct relevance to our meta-analysis, (c) several of those that were located had been converted into published articles (e.g., Biagini, 2011; Ciccomascolo, 1995), and (d) results from unpublished studies (e.g., Connon, 2011; Long, 1999) were generally consistent with the published studies included in the meta-analysis.

\section{Search Results}

Following the recommendations of Moher, Liberati, Tetzlaff, and Altman (2009), a summary of the search process is shown in Figure 2. Search strategies identified 16,012 citations related to music in physical activity. Following the removal of duplicates, the title and abstract of 14,486 citations were screened and 383 studies were targeted for detailed review. In total, 244 studies were excluded after full-text screening because they did not meet all inclusion criteria. Of these, 48 were outside the domain of interest (i.e., not in an exercise or sport setting), 17 did not meet the definition of having used a music intervention, 90 did not measure one or more of the outcome variables of interest, $21 \mathrm{did}$ not include a control group, 60 provided insufficient data to enable appropriate calculation of effect sizes, even after authors had been contacted to obtain additional data, six studies used special populations, one was a case study, and one did not provide an objective measure of performance. The net result of the search process was that 139 studies yielding 600 effects based on 3,599 participants were retained for entry into the meta-analysis.

\section{Moderator Variable Coding}

In addition to the primary aim of quantifying effects of music for each outcome variable assessed (FS, HR, V ${ }_{2}, \mathrm{RPE}$, performance), a secondary aim was to establish the moderating influence of a range of variables that would advance understanding of the

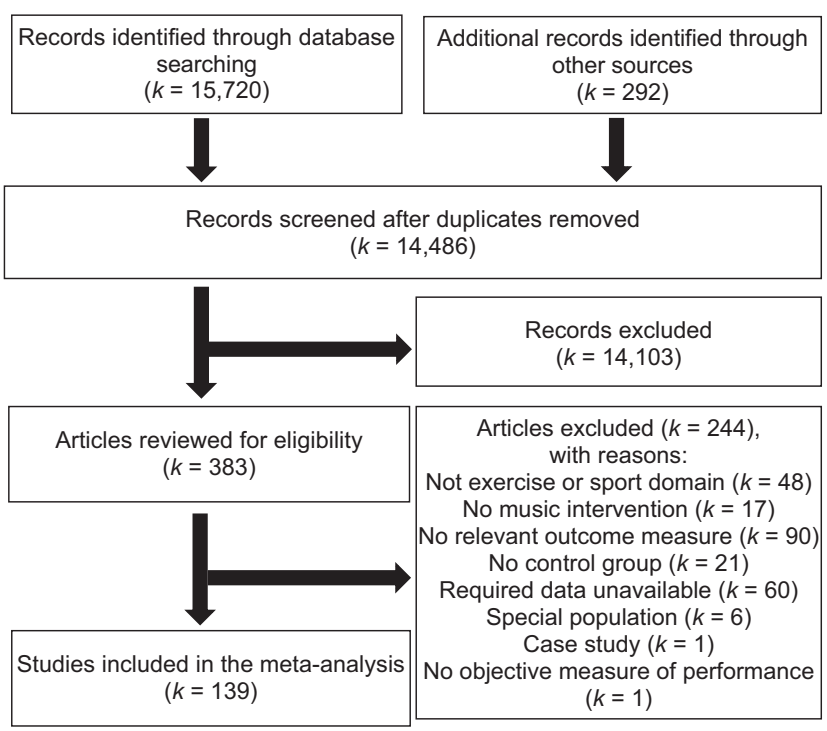

Figure 2. Study flow diagram. 
field and were relevant in terms of theory, underlying mechanisms, and/or applications. These variables included the characteristics of the study and the domain in which it was conducted, the characteristics of the music used in the study and how it was used, the characteristics of the study participants, and the characteristics of the physical activity used.

Included studies were first coded for domain characteristics (exercise, sport), participant characteristics (male, female; child/ youth, adult/college, senior; trained, untrained), music characteristics (pretask, synchronous, asynchronous; motivational, neutral; researcher-selected, self-selected; fast tempo, low-to-medium tempo; lyrical, instrumental), activity characteristics (running, walking, cycling, strength, other; low-to-moderate intensity, high intensity; weight-bearing, nonweight-bearing), and study characteristics (publication year; field study, laboratory study; between-subjects design, within-subjects design; study quality). Some characteristics were included for descriptive purposes (e.g., sex, age group) but were of less interest scientifically given the absence of any theoretical or empirical indication that they would moderate the effect of music, and hence were excluded from moderator analyses. Most of these variables are self-explanatory but some require definition.

In the context of the present meta-analysis, exercise refers to noncompetitive physical activities (e.g., walking, running, weight training) excluding those where music is inherent to the activity (e.g., dance, rhythmic gymnastics, ice skating) and those outside the area of interest (e.g., gardening, housework), whereas sport refers to codified, competitive physical activities, including actual races (e.g., 60-m sprinting, 400-m running, ultramarathon), and simulated races (e.g., 200-m swimming, 2-km rowing ergometry, $10-\mathrm{km}$ cycling time trials). Pretask music refers to where participants listened to music immediately prior to completing an activity, synchronous music listening refers to where participants completed activities in time to the music (i.e., auditory-motor synchronization), and asynchronous music refers to background or ambient music where no conscious synchronization occurred. It should be noted that background or ambient music does not refer to music that is played quietly in the background but rather music that is not intended to facilitate auditory-motor synchronization.

Motivational music refers to music that stimulates or inspires physical activity, whereas neutral music (sometimes referred to as oudeterous music, from the Greek word for neutral) refers to music that is neither motivational nor demotivational. The motivational qualities of music are typically assessed using the Brunel Music Rating Inventory (BMRI; Karageorghis et al., 1999) or its derivatives. Fast music refers to music with a tempo $>120 \mathrm{bpm}$ whereas slow-to-medium music refers to music with a tempo $\leq 120 \mathrm{bpm}$.

Coding for researcher-selected and self-selected music was generally unambiguous, although there were studies in which participants selected music tracks from a list provided by researchers (e.g., Ruscello, D’Ottavio, Padua, Tonelli, \& Pantanella, 2014) and others in which researchers selected tracks from a list provided by participants (e.g., Crust, 2004b; Dyer \& McKune, 2013). In these instances, we considered the range of music choices available to participants, and coded the former cases as researcher-selected and the latter as self-selected.

Low-to-moderate intensity refers to activity performed at $<70 \%$ of aerobic capacity, whereas high intensity refers to activity performed at $\geq 70 \%$ of aerobic capacity. For most healthy people, at exercise intensities $\geq 70 \%$ of capacity, breathing becomes labored, lactic acid begins to accumulate in the musculature causing physical discomfort, and attention tends to switch from external cues, such as music, to internal, fatigue-related cues (Rejeski, 1985; Tenenbaum, 2001). In practical terms, for most healthy people under the age of 50 years, a gentle walk or light jog would typify activity that was $<70 \%$ of capacity, whereas a fast run or sprint would typify activity that was $\geq 70 \%$ of capacity. All exercise-toexhaustion protocols were coded as high intensity. Trained refers to participants who engaged in regular physical activity ( $\geq 3$ times/ wk) whereas untrained refers to participants for whom physical activity was not habitual. Weight-bearing refers to activities such as walking and running, whereas nonweight-bearing refers to activities such as swimming and cycling.

All eligible outcomes that included repeated measurements at different time points were considered as one unit of evidence and coded accordingly. An additional coding variable was included to facilitate the identification of experimental groups.

\section{Coder Reliability}

To guard against coder drift (i.e., changes in coder output caused by boredom/fatigue and/or practice effects) each study was coded multiple times by doctoral-qualified researchers (MLC, OVM, RLP-S) and discrepancies resolved by two experts in the field of sport and exercise psychology (PCT, CIK). Intra-coder reliability calculations showed the per-case agreement rate to be .99 . Additionally, to quantify inter-coder reliability for moderator codes, a random sample of 20 studies was coded by two members of the research team (MLC, PCT). The per-case agreement rate was .94, which was within the range of acceptability (Shaughnessy, Zechmeister, \& Zechmeister, 2006).

\section{Study Quality}

The quality of each study was assessed using the Cochrane Collaboration tool (Higgins et al., 2011). No included studies were rated as high quality, given that it is impossible to blind participants to the presence or absence of a music intervention (see, e.g., Clark et al., 2012), and hence there is no scope for double-blind, placebo-controlled designs. All included studies were therefore rated as either low or moderate quality.

\section{Effect Size and Standardizer Calculations}

Johnson and Huedo-Medina's (2013) Monte Carlo analyses were used to guide the selection of optimal estimations of the effect size and standardizer. These scholars showed that the standardized means difference (SMD) yields stronger statistical inferences than unstandardized measures, in terms of bias and efficiency, under most conditions. Accordingly, SMDs were estimated for all outcome variables, regardless of whether the outcome measure of interest had been reported using the same metric or not. Many possible equations are available for the SMD and its variance with repeated-measures designs (within- or betweensubjects), but simulations suggest that some equations are preferable to others under certain conditions (Johnson \& Huedo-Medina, 2013). Consequently, Hedges' $g$ was calculated according to Hedges (1981) and Becker (1988) for between-subjects and 
within-subjects study designs, respectively. Similarly, the raw score metric for a total effect size (Hedges, 1981) and changescore metric (Gibbons, Hedeker, \& Davis, 1993) equations were adopted to compute the variance for between-subjects and withinsubjects study design, respectively.

\section{Multilevel Meta-Analysis}

An important requirement in meta-analytic approaches is the independence of effect sizes included in the data set. Traditional approaches to address dependence between effect sizes aim to retain one effect size per experiment and typically consist of eliminating effect sizes or estimating weighted averages of dependent effect sizes (Assink \& Wibbelink, 2016). These methods result in both loss of statistical power and information about potential moderators (Assink \& Wibbelink, 2016). Multivariate approaches can account for three different variance components: sampling variance of the extracted effect sizes at level 1 (i.e., between participants); variance between effect sizes extracted from the same study at level 2 (i.e., between outcomes measured in the same participants); and variance between studies at level 3 . The multilevel approach offers the advantage over other techniques of not requiring correlations between outcomes to be known, as such correlations are only seldom reported in primary studies and thus difficult to obtain. A multilevel meta-analysis was therefore carried out by applying the rma.mv function in the metafor package which can be invoked in the R statistical software environment (Assink \& Wibbelink, 2016; Viechtbauer, 2010).

The data set was checked for outlying effect sizes by screening for effect sizes $\geq \pm 3.29$ (Tabachnick \& Fidell, 2018). This prompted the removal of two extreme outlier effects for perceived exertion ( $g=21.52$ and 15.13; Di Cagno et al., 2015), leaving 598 effect sizes to be included in the overall model (see Figure 3). First, the analysis was carried out for the overall model with the inclusion of all outcome variables, then with the five outcome variables as moderators. As this latter analysis demonstrated that outcome is a significant moderator, we proceeded with separate analyses for each outcome. In turn, if significant heterogeneity was detected for separate outcomes, analysis of relevant moderators was carried out. Heterogeneity is reported as the $Q$ statistic. All tests for moderators were carried out using robust standard errors and reported as an $F$ value. For significant moderators with more than two categories, Tukey's Honestly Significant Difference
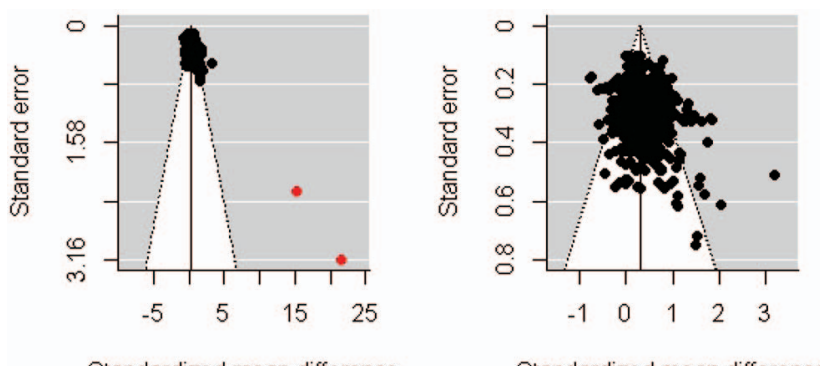

Standardized mean difference

Standardized mean difference

Figure 3. Funnel plots for the overall model, with outliers in red (left), and without outliers (right). See the online article for the color version of this figure.
(HSD) comparison among means was computed from the results of moderator tests with robust standard errors.

In addition to funnel plots, publication bias was tested using Egger's regression test (Egger, Davey Smith, Schneider, \& Minder, 1997) with $90 \%$ confidence intervals. This test detected statistically significant asymmetry for performance effect sizes. This prompted us to remove two comparatively larger effect sizes related to performance that were derived from the Di Cagno et al. (2015) study, for which RPE effect sizes had been previously identified as outliers. Removal of the Di Cagno et al. study had only a very limited impact on the statistics obtained and did not affect the study conclusions, therefore only the results of this latter analysis are reported. This exclusion alone could not account for potential publication bias, which was still detectable.

\section{Results}

The meta-analysis included 139 studies involving 3,599 participants, having considered a 107-year period, from 1911-2017. Effects of music were investigated for five outcome variables; namely, psychological responses, as assessed by the Feeling Scale (FS); physiological responses, as assessed by heart rate (HR) and oxygen consumption $\left(\mathrm{VO}_{2}\right)$; psychophysical responses, as assessed by the rating of perceived exertion (RPE); and physical performance, as assessed by objective indices described earlier. All included studies, associated statistics, and moderator codes for study, participants, music, and activity characteristics are shown in Appendix A in the online supplemental materials.

Table 1 shows the number of effects, studies, and participants for each outcome variable. Table 2 presents the overall effect for all outcome variables collectively $(g=0.29, p<.001)$ and confirmation of significant heterogeneity $\left(Q_{597}=1,239, p<\right.$ $.001)$. Further analysis identified significant differences in effect sizes among the outcome variables $\left(F_{4,593}=7.42, p<.001\right)$ and significant heterogeneity $\left(Q_{593}=1,049, p<.001\right)$. Music was associated with significant beneficial effects for FS $(g=0.48, p<$ $.001)$, performance $(g=0.31, p<.001)$, RPE $(g=0.22, p<$ $.001)$, and $\dot{\mathrm{VO}}_{2}(g=0.17, p<.01)$, but no significant benefit for HR $(g=0.07, p>.05)$. Benefits varied in magnitude across outcome variables, with a moderate beneficial effect of music on FS scores, whereas the benefits for performance, RPE and $\dot{\mathrm{V}}_{2}$ were small although significant. Overall, listening to music was associated with more positive feelings, improved physical performance, reduced perceived exertion, and more efficient oxygen utilization.

Following the recommendations of Sterne and colleagues (Sterne \& Egger, 2001; Sterne \& Harbord, 2004; Sterne et al., 2011), a series of funnel plots of per study standard error by standard difference in group means was produced and assessed for evidence of asymmetry (see Figure 4). Egger's test (Egger et al., 1997) indicated significant asymmetry and therefore potential publication bias for performance but not for the other outcome variables. Because of potential publication bias, the summary effect size for performance may be slightly inflated.

Moderator analyses were conducted for outcome variables where significant heterogeneity was identified. $Q$ values indicated heterogeneity for HR, performance, and RPE, but not for FS and $\mathrm{VO}_{2}$ (see Table 2). Hence, no moderator analyses were conducted for $\mathrm{FS}$ and $\mathrm{VO}_{2}$. Moderation analyses for $\mathrm{HR}$ were conducted but 
Table 1

Number of Studies, Effects, and Participants by Outcome Variable

\begin{tabular}{lccc}
\hline \multicolumn{1}{c}{ Construct } & $\begin{array}{c}\text { Number of } \\
\text { studies }\end{array}$ & $\begin{array}{c}\text { Number of } \\
\text { effects }\end{array}$ & $\begin{array}{c}\text { Total } \\
\text { participants }\end{array}$ \\
\hline Feeling Scale & 29 & 95 & 638 \\
Heart rate & 35 & 68 & 744 \\
Performance & 109 & 292 & 2,773 \\
Perceived exertion & 54 & 123 & 1,268 \\
Oxygen consumption & 9 & 20 & 149 \\
Total & 139 & 598 & 3,599 \\
\hline
\end{tabular}

Note. Totals indicate the overall number of studies, effects, and participants included in the meta-analysis rather than the sum of the previous five rows. Many studies included more than one outcome variable.

are not reported because no significant benefits of music on HR were found for any moderator. Results of moderation analyses for performance and RPE are shown in Tables 3 and 4, respectively. Two significant moderators of performance were found, with exercise participants deriving greater benefit than sport participants $(g=0.35$ vs. $g=0.15 ; p<.001)$ and fast-tempo music associated with greater benefits than slow-to-moderate tempo music $(g=0.38$ vs. $g=0.21 ; p<.001)$. No significant moderation effects were identified for perceived exertion (see Table 4).

\section{Discussion}

Results of the meta-analysis provide evidence that music listening is associated with beneficial effects in the context of exercise and sport for four of the five outcome variables investigated (see Table 2). The model tested indicated that music listening significantly enhanced feeling states, increased physical performance, reduced perceived exertion, and improved oxygen consumption efficiency across a broad range of exercise- and sport-related tasks. The overall effect of music, when all outcome measures were conglomerated, was small in magnitude but reliable ( $g=0.29$, CI [0.24-0.34]). Notably, the effect size for FS scores was significantly greater than for all other outcome variables, and performance effects were greater than for $\mathrm{HR}$ and $\mathrm{VO}_{2}$.

\section{Music and Affective Responses}

Affective responses (i.e., FS scores) were associated with the largest standardized mean effect $(g=0.48)$ among the outcome variables (see Table 1). The past decade has witnessed a surge of enthusiasm in favor of fuller consideration of the role of positive affect and enjoyment in the prescription of physical activity (e.g., Ekkekakis, Hargreaves, \& Parfitt, 2013; Ekkekakis et al., 2020). An essential message from such sources is that if individuals are not motivated by self-determined influences, such as enjoyment and the accomplishment of valued personal goals, then they are unlikely to engage in physical activity on a long-term basis, regardless of how often they are informed of its potential health benefits (Brand \& Ekkekakis, 2018). Thus, the promotion of self-determined forms of behavioral regulation (Ryan \& Deci, $2000,2017)$ is likely to foster the maintenance of physical activity behaviors. Accordingly, there is a need to identify which aspects of physical activity (e.g., intensity, duration, modality, environment, etc.) can be manipulated to promote enjoyment and positive affect. For example, the promotion of lifestyle physical activity with music, such as getting off the bus a stop early en route to work and walking to musical accompaniment, might assist people to elevate their daily energy expenditure and arrive at work with a more positive mindset (Foster et al., 2011; Franěk, van Noorden, \& Režný, 2014).

The affective benefits associated with music in exercise and sport contexts can be explained with reference to Juslin's (2013) proposed psychological mechanisms. In particular, the use of stimulative or motivational music implicates the brain stem reflex, wherein music stimulates the central nervous system in a manner that reflects the heightened physiological arousal associated with high-intensity activity (see Chapados \& Levitin, 2008; Karageorghis \& Jones, 2014). Further, when such music is used, there is scope for the phenomenon of emotional contagion to occur. This entails the exerciser or athlete catching the emotional qualities of a piece of music.

The demonstrated music-affective valence link has two important implications. First, and most importantly, the inclusion of music in physical activity settings is likely to enhance participant enjoyment, promote adherence, and therein maximize health benefits (Madison, Paulin, \& Aasa, 2013; Stork et al., 2019). One notable absence from the literature is the lack of longitudinal investigations that seek to establish links between music applications, enhanced affect, and physical activity adherence. Future longitudinal investigations are required to provide exercise and health professionals with a stronger empirical basis for the musicexercise adherence link. Such research would hold particular value if it focused on at-risk populations, including prediabetics, the

Table 2

Standardized Mean Effects of Music in Physical Activity by Outcome Variable

\begin{tabular}{lcccccl}
\hline \multicolumn{1}{c}{ Effect } & $g$ & $S E$ & $95 \% \mathrm{CI}$ & $Q(d f)$ & $F$ & Tukey's HSD \\
\hline Overall effect & $.29^{\dagger}$ & .03 & {$[.24, .34]$} & $1,239(597)^{\dagger}$ & & \\
Outcomes & & & & $1,049(593)^{\dagger}$ & $7.42^{\dagger}$ & \\
$\quad$ Feeling Scale & $.48^{\dagger}$ & .04 & {$[.39, .56]$} & $114(94)$ & & $<\mathrm{FS}^{\dagger}$ \\
Heart rate & .07 & .05 & {$[-.03, .16]$} & $88(67)^{*}$ & $<37(289)^{\dagger}$ & $<\mathrm{FS}^{\dagger},>\mathrm{HR}^{*}, \mathrm{VO}_{2}^{*}$ \\
Performance & $.31^{\dagger}$ & .03 & {$[.25, .36]$} & 437 & $<\mathrm{FS}^{\dagger}$ \\
Perceived exertion & $.22^{\dagger}$ & .04 & {$[.14, .30]$} & $359(122)^{\dagger}$ & $<\mathrm{FS}^{\dagger}$ \\
Oxygen consumption & $.15^{\dagger}$ & .06 & {$[.02, .27]$} & $7(19)$ & \\
\hline
\end{tabular}

Note. $g=$ standardized mean effect size (Hedges' $g$ ); Tukey's $H S D=$ Tukey's Honestly Significant Difference; FS $=$ Feeling Scale; $\mathrm{HR}=$ heart rate; $\dot{\mathrm{VO}}_{2}=$ oxygen consumption.

${ }^{\dagger} p<.001 .{ }^{*} p<.01 .{ }^{*} p<.05$. 


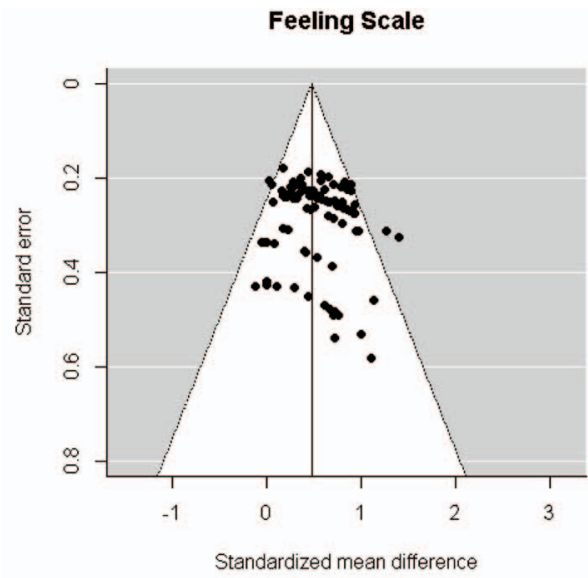

Performance

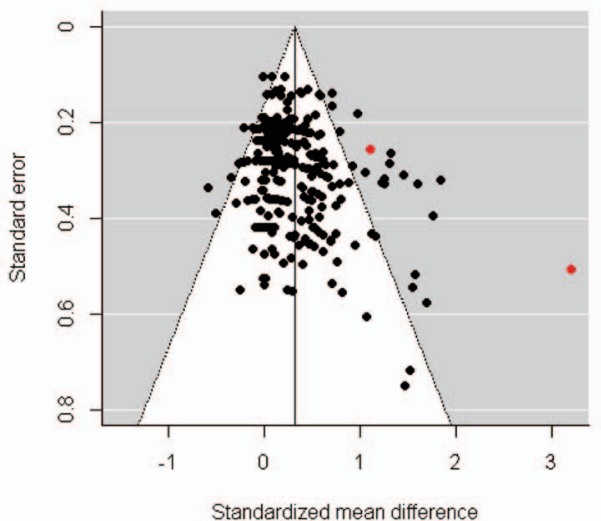

$\dot{\mathrm{VO}}_{2}$

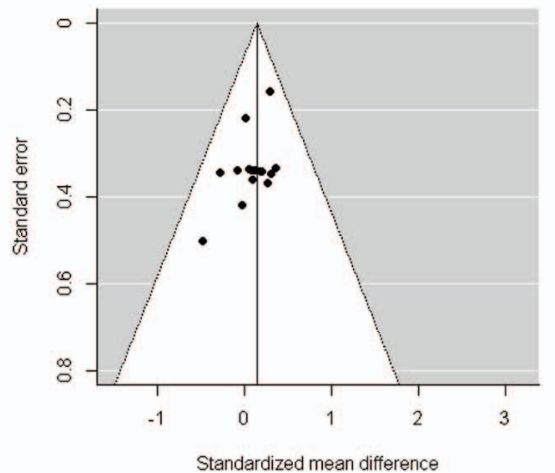

Heart rate

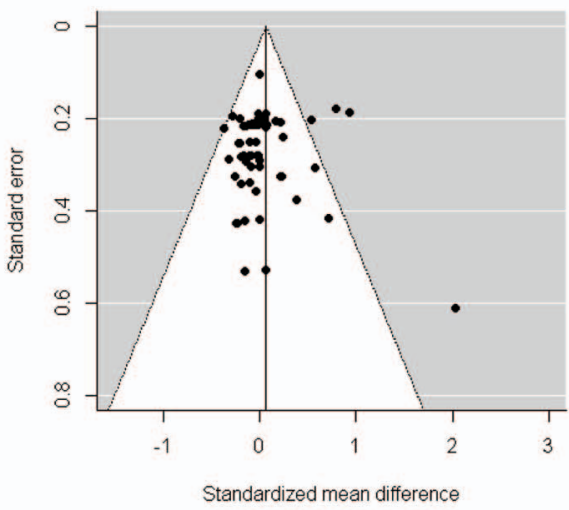

RPE

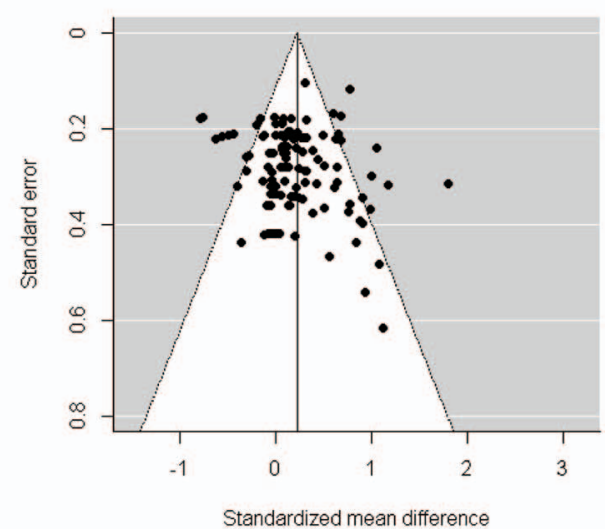

Figure 4. Funnel plots for Feeling Scale, heart rate, performance, RPE, and $\mathrm{VO}_{2}$. Positive effects indicate improved outcomes associated with music. See the online article for the color version of this figure.

clinically obese, and the sedentary (see Hutchinson, Karageorghis, \& Black, 2017; Jones, Karageorghis, \& Ekkekakis, 2014).

Counter to theoretical predictions, music tempo did not significantly moderate affective responses, challenging findings from investigations into music-tempo preferences during exerciserelated tasks (e.g., Karageorghis, Jones, \& Stuart, 2008; Karageorghis et al., 2011). The lack of moderation might be explained by the common use of inspirational, energizing and/or rhythmically complex tracks at tempi $<120$ bpm (e.g., Bigliassi et al.,
2016, 2017). It is plausible that slow-to-medium tempo music had a soothing effect during high-intensity bouts of activity resulting in positive scores for affective valence (e.g., Karageorghis \& Jones, 2014; Terry, Karageorghis, et al., 2012).

Physical activity intensity did not moderate music-induced affective responses in the present meta-analysis, which is indicative that music can provide psychological benefits across the full gamut of intensities. When people self-select physical activity intensity, they typically choose an intensity that engenders a positive affec- 
Table 3

Standardized Mean Effects of Music on Performance by Moderator Variable

\begin{tabular}{|c|c|c|c|c|c|c|}
\hline Effect & $k$ & $g$ & $S E$ & $95 \% \mathrm{CI}$ & $Q(d f)$ & $F$ \\
\hline Overall effect & & $.31^{\dagger}$ & .03 & {$[.25, .36]$} & $437(289)^{\dagger}$ & \\
\hline Design & & & & & $436(288)^{\dagger}$ & 1.03 \\
\hline Within & 257 & .30 & .07 & {$[.15, .45]$} & & \\
\hline Between & 33 & .38 & .07 & {$[.24, .51]$} & & \\
\hline Quality & & & & & $431(288)^{\dagger}$ & 1.61 \\
\hline Low & 175 & .34 & .04 & {$[.25, .42]$} & & \\
\hline Moderate & 115 & .26 & .06 & {$[.14, .38]$} & & \\
\hline Location & & & & & $436(288)^{\dagger}$ & 2.04 \\
\hline Field & 77 & .24 & .05 & {$[.13, .34]$} & & \\
\hline Laboratory & 213 & .33 & .07 & {$[.20, .46]$} & & \\
\hline Domain & & & & & $427(288)^{\dagger}$ & $16.90^{\dagger}$ \\
\hline Exercise & 219 & .35 & .04 & {$[.27, .43]$} & & \\
\hline Sport & 71 & .15 & .05 & {$[.05, .25]$} & & \\
\hline Level & & & & & $432(287)^{\dagger}$ & 1.71 \\
\hline Trained & 181 & .27 & .04 & {$[.20, .34]$} & & \\
\hline Untrained & 50 & .45 & .10 & {$[.25, .65]$} & & \\
\hline Mixed/Unspecified & 59 & .29 & .07 & {$[.14, .43]$} & & \\
\hline Mode & & & & & $433(287)^{\dagger}$ & 1.79 \\
\hline Pretask & 36 & .21 & .07 & {$[.07, .35]$} & & \\
\hline Asynchronous & 233 & .31 & .04 & {$[.24, .38]$} & & \\
\hline Synchronous & 21 & .44 & .11 & {$[.22, .65]$} & & \\
\hline Selection & & & & & $434(287)^{\dagger}$ & .33 \\
\hline Researcher & 188 & .32 & .04 & {$[.25, .39]$} & & \\
\hline Self & 98 & .29 & .04 & {$[.20, .38]$} & & \\
\hline Unspecified & 4 & .23 & .16 & {$[-.08, .54]$} & & \\
\hline Tempo $^{a}$ & & & & & $401(287)^{\dagger}$ & $13.45^{\dagger}$ \\
\hline Fast & 130 & .38 & .04 & {$[.30, .45]$} & & \\
\hline Slow/Mediu & 77 & .21 & .03 & {$[.14, .27]$} & & \\
\hline Mixed/Unspecified & 83 & .26 & .05 & {$[.17, .36]$} & & \\
\hline Intensity & & & & & $420(287)^{\dagger}$ & 1.77 \\
\hline High & 212 & .27 & .04 & {$[.20, .35]$} & & \\
\hline Low/Moderate & 72 & .39 & .06 & {$[.27, .52]$} & & \\
\hline Mixed/Unspecified & 6 & .27 & .15 & {$[-.04, .58]$} & & \\
\hline
\end{tabular}

Note. $\quad k=$ number of effects; $g=$ standardized mean effect size (Hedges' $g$ ). Only moderator variables with significant $Q$ statistics are reported.

a Tukey's Honestly Significant Difference $=$ fast $>$ slow $/$ medium.

${ }^{\dagger} p<.001$.

tive response (e.g., Parfitt, Alrumh, \& Rowlands, 2012; Williams, 2008). This is consistent with the hedonic principle, wherein individuals seek to maximize pleasure and minimize pain (Higgins, 1997). Considering this principle in light of the present findings, it appears sensible to promote applications of music in physical activity programs with the primary aim of promoting enjoyment rather than physiological benefits (Nielsen et al., 2014). A limiting factor for many exercisers is negative affect during physical activity at higher levels of intensity (Ekkekakis \& Acevedo, 2006; Rose \& Parfitt, 2010); hence an emphasis on positive affect and enjoyment may provide positive consequences for adherence and corollary motivational benefits (e.g., higher levels of self-determined motives). The peak-end rule described earlier (Parfitt \& Hughes, 2009) is particularly salient, given that the affective experience of exercisers may guide future participation decisions (Williams et al., 2012).

The affective benefits associated with the use of music during high-intensity exercise as well as low/moderate-intensity exercise can be linked to the dual-mode theory of affect (Ekkekakis, 2003), which posits interindividual variability in the interpretation of physiological symptoms during strenuous exercise. Our findings highlight that symptoms of fatigue appear to be ameliorated and affective valence scores directed toward the positive end of the scale when music is present (e.g., Edworthy \& Waring, 2006; Hutchinson \& Karageorghis, 2013).

In sum, the absence of moderation effects for affective valence suggests that music is likely to engender positive responses during exercise on a fairly consistent basis regardless of personal, situational, and musical characteristics. This suggests a potential benefit for exercisers, given that they do not need to adhere to a strict set of guidelines to derive affective benefits. Nonetheless, to maximize the benefits, well-controlled studies in this literature do illustrate that self-selection of upbeat music with personally emotive qualities is worthy of consideration (e.g., Hutchinson et al., 2018; Stork et al., 2015).

\section{Music and Physiological Functioning}

The present results suggest that music can exert a small but significant benefit on oxygen utilization during physical activity. This is consistent with mounting evidence from medical studies that show beneficial effects of music on cardiovascular and respiratory functioning (e.g., Bernardi et al., 2009; Miller, Beach, Mangano, \& Vogel, 2008; Sleight, 2013). For example, Miller et al. (2008) showed that blood-flow efficiency increased by $26 \%$ after listening to enjoyable music but decreased by $6 \%$ after listening to anxiety-inducing music. Improved blood flow efficiency would, in turn, lead to improved oxygen utilization. Moreover, Sleight (2013) reported that beneficial effects of music on physiological functioning appear to accrue primarily on the basis of inherent characteristics of music and independently of preferences.

A credible explanation for the observed effect is that the rhythmical elements of music enhance the biomechanical or neurome-

Table 4

Standardized Mean Effects of Music on Perceived Exertion by Moderator Variable

\begin{tabular}{lccccccc}
\hline \multicolumn{1}{c}{ Effect } & $k$ & $g$ & $S E$ & $95 \%$ CI & $Q(d f)$ & $F$ \\
\hline Overall effect & & $.22^{\dagger}$ & .04 & {$[.14, .30]$} & $359(122)^{\dagger}$ & \\
Quality & & & & & $341(121)^{\dagger}$ & 3.83 \\
$\quad$ Low & 68 & .28 & .07 & {$[.15, .42]$} & & \\
$\quad$ Moderate & 55 & .12 & .08 & {$[-.04, .29]$} & & \\
Level & & & & & $328(120)^{\dagger}$ & 1.64 \\
$\quad$ Trained & 80 & .15 & .04 & {$[.06, .24]$} & & \\
$\quad$ Untrained & 29 & .27 & .09 & {$[.08, .46]$} & & \\
$\quad$ Unspecified & 14 & .42 & .20 & {$[.02, .81]$} & & \\
Selection & & & & & & \\
$\quad$ Researcher & 85 & .18 & .05 & {$[.08, .27]$} & & \\
$\quad$ Self & 38 & .31 & .10 & {$[.12, .51]$} & & \\
Tempo & & & & & & \\
$\quad$ Fast & 51 & .16 & .06 & {$[.04, .29]$} & & \\
$\quad$ Slow/Medium & 26 & .13 & .07 & {$[-.01, .26]$} & & \\
$\quad$ Unspecified & 46 & .33 & .10 & {$[.14, .52]$} & & \\
$\quad$ Intensity & & & & & \\
$\quad$ High & 88 & .23 & .06 & {$[.12, .33]$} & & \\
$\quad$ Low/Moderate & 33 & .20 & .08 & {$[.05, .36]$} & & \\
$\quad$ Unspecified & 2 & .21 & .15 & {$[-.10, .52]$} & & \\
\hline
\end{tabular}

Note. $k=$ number of effects; $g=$ standardized mean effect size (Hedges' $g$ ). Only moderator variables with significant $Q$ statistics are reported. ${ }^{\dagger} p<.001$. 
chanical efficiency of physical movements during exercise (Bacon et al., 2012). For example, running in time with music helps to regulate stride patterns and promotes fluidity, meaning that fewer micro-adjustments to movement patterns are required, resulting in slightly reduced energy cost for a given workload (Bood et al., 2013; Terry, Karageorghis, et al., 2012). Such effects, no matter how small in magnitude, should logically contribute to improved physical performance, particularly in long-duration activities that are rhythmical and repetitive in nature (e.g., running, cycling, and swimming).

Examination of $\dot{\mathrm{VO}}_{2}$ as an outcome variable in music-related studies has invariably occurred in a laboratory setting. Although a laboratory environment provides the required level of control and equipment for oxygen consumption to be recorded accurately, such an environment can obfuscate the influence of music, given the attentional demands and potential anxiety-inducing nature of the apparatus required to take such measures (see Karageorghis \& Terry, 1997). It is noteworthy that in many studies involving respiratory analyses, the reported benefits of music were negligible (e.g., Dyer \& McKune, 2013; Hagen et al., 2013).

The examination of heart rate has occurred in a broad range of physical activity contexts, owing to the ease of data capture using strap-on monitors. The lack of a generalized effect might be attributed, in part, to the effects of music on the functioning of the cardiorespiratory system independently of exercise-related tasks (see, e.g., Ooishi et al., 2017). Slow-tempo music during moderateto-vigorous exercise can slightly reduce heart rate (e.g., Copeland \& Franks, 1991), whereas fast-tempo music can slightly increase heart rate during low-intensity exercise (e.g., Nethery, 2002). It is also the case that auditory-motor synchronization overrides how bodily pulses, such as heart rate, entrain to music (i.e., it becomes the dominant form of entrainment). On balance, based on the findings of a few well-controlled studies (e.g., Karageorghis et al., 2009; Terry, Karageorghis, et al., 2012), it seems plausible that appropriately selected music can lead to small benefits in physiological efficiency, which have implications in terms of performance gains in endurance-type activity.

\section{Music and Perceived Exertion}

The significant influence of music on ratings of perceived exertion (RPE) can be explained primarily, although not exclusively, by the notion that music distracts exercisers from unpleasant, fatigue-related sensations (Rejeski, 1985; Tenenbaum, 2001). There are at least three considerations to bear in mind when interpreting the overall effect size for RPE $(g=0.22)$. First, where studies have implemented prescribed intensities, which ensured that the physical activity was conducted at controlled work rates, music has typically been associated with reductions in RPE compared with completion of the same workload without music (e.g., Hutchinson \& Karageorghis, 2013; Lim et al., 2014). Second, during high-intensity physical activity, the distraction effect of music can be negated by powerful interoceptive signals of physical discomfort associated with the activity and the benefit to RPE may be lost (e.g., Karageorghis et al., 2009; Stork et al., 2015), although in studies using elite performers, the benefits of music on RPE have been observed even during high-intensity activity (e.g., Jarraya et al., 2012; Terry, Karageorghis, et al., 2012).
Third, some studies, especially those that have sought greater ecological validity, have used research designs that confounded the effects of work output on RPE. Typical of such studies was Atkinson et al.'s (2004) test of the effects of music on work rate during a cycling time trial, wherein highly trained cyclists selfselected their work rate, in a manner akin to how they would perform during a 10-km competition. The results showed that music was associated with significantly faster completion time coupled with significantly higher RPE, suggesting that although the music may have assisted the cyclists to go faster, they were aware of the objective increase in work rate and rated their perceived exertion accordingly.

The moderation effect of work intensity was nonsignificant, suggesting that reductions in RPE can be achieved across the full range of exercise intensities. This runs counter to theoretical propositions, which hold that because of the predominance of interoceptive cues at high intensities, music is less likely to assuage perceived exertion (Karageorghis, 2016; Tenenbaum, 2001). It is important to acknowledge two methodological characteristics of the literature. First, very few studies used biological markers (e.g., ventilatory threshold) to set exercise intensity (e.g., Jones et al., 2014; Lim et al., 2014), creating uncertainty about the accuracy of the intensity at which experimental participants were exercising. Second, the present analysis used only two broad categories of intensity for the test of moderation, high ( $\geq 70 \%$ aerobic capacity) and low-tomoderate $(<70 \%$ aerobic capacity). Experimental work has shown music to be largely ineffective in reducing RPE beyond $\sim 75 \%$ of aerobic capacity (e.g., Boutcher \& Trenske, 1990; Karageorghis et al., 2009).

There is some empirical evidence to suggest that the attentional characteristics of exercisers and athletes influence how music is used at different physical activity intensities (Hutchinson \& Karageorghis, 2013). At high exercise intensities, it appears that those individuals categorized as associators (i.e., those with a disposition toward an internal, task-relevant focus) tend to use music by coupling it with task demands (e.g., by synchronizing movement patterns to the beat, looking for inspiration in the lyrics; Hutchinson \& Karageorghis, 2013). There is evidence that highly trained exercisers or elite athletes tend to associate rather than dissociate (e.g., Baker, Côté, \& Deakin, 2005; Gabana, Van Raalte, Hutchinson, Brewer, \& Petitpas, 2015) and so the finding that RPE was reduced by music, even at high work intensities, may relate to the attentional characteristics of participants. An important avenue for future investigation is to consider attentional style as a potential moderator of the effects of music listening on RPE (see Hutchinson \& Karageorghis, 2013).

There are plausible explanations for the lack of other moderation effects. For example, there are no theoretical reasons to suggest that the person selecting the music, nor the tempo at which the music is played, should moderate RPE. Music has a tendency to absorb an individual's attention and thus reduce RPE regardless of who selects the music and how fast the tempo might be. The extant literature does not have the glanularity needed to test moderation across a range of tempi bands; nonetheless, experimental studies comparing music tempi have not found differential effects on RPE (e.g., Edworthy \& Waring, 2006). 


\section{Music and Performance}

The effect of music on physical performance is perhaps the area in which practitioners, particularly those operating in the sport domain, have the most interest. Overall, music had a small beneficial effect coupled with a small standard error $(g=0.31, S E=$ $0.03)$, suggesting a high degree of confidence in this finding. Two moderating effects were identified (see Table 3). First, the exercise domain yielded a stronger effect than the sport domain. This was expected, given that researchers can exert greater control over participant kinematics during exercise than during sport. The latter often involves well-established motor patterns (e.g., Bigliassi, Dantas, Carneiro, Smirmaul, \& Altimari, 2012), coactive tasks (e.g., Miller \& Donohue, 2003), or open environments (e.g., Aweau \& Redus, 2015).

The relatively few degrees of freedom involved in exercise tasks reduces potential confounds and increases the propensity for performance benefits. Many of the sport-related studies were conducted in field settings (e.g., Arazi, Ghanbari, Zarabi, \& Rafati, 2017; Hall \& Erickson, 1995), meaning that several of the environmental controls that researchers typically employ (e.g., sterile visual surroundings, temperature regulation, social isolation, no verbal encouragement) could not be implemented. One advantage of sport-related studies is that they do shine a light on how music can benefit physical performance in ecologically valid settings.

Music tempo also emerged as a moderating variable. As expected, fast-tempo music yielded a stronger performance benefit than slow-to-medium tempo music. North and Hargreaves (2008) highlighted the association between the stimulative properties of a musical work and the function that it serves in different listening situations. Given the high-energy/activation state typically required for optimal performance in exercise or sport, the stronger effect for fast-tempo music reflects what we know about physiological arousal and musical aesthetics (see, e.g., Karageorghis, 2020 for a review). Notably, many studies in our meta-analysis did not provide details of music tempi, which renders both interpretation of findings and study replication extremely challenging.

Across the music-in-physical activity literature, the crucial cutoff point for music tempo appears to be $120 \mathrm{bpm}$, which is twice the resting heart rate of healthy adults, the preferred walking step frequency in humans, a tempo that reflects natural rhythmicity (e.g., while finger tapping), and a seemingly magic number in terms of human activation (see Schneider et al., 2010 for a discussion). This is also the cutoff we used to differentiate between slow-to-medium tempo and fast-tempo music. An analysis of more than 70,000 pieces of modern music (1960-1990) by MacDougall and Moore (2005) showed $120 \mathrm{bpm}$ to be the dominant tempo. We can conclude that human movement and perception are somehow bound to this tempo; indeed, it is with tracks at this precise tempo that deejays routinely lure people onto a dance floor (see Dahl, Huron, Brod, \& Altenmüller, 2014).

No moderating effect was found for delivery mode, although the synchronous application of music yielded a stronger effect for performance than asynchronous and pretask applications. The majority of studies using pretask music were in sport-related contexts (e.g., Hall \& Erickson, 1995; Sherman \& Richmond, 2013) where even a small beneficial effect engendered by music in the crucial precompetition phase can prove decisive in performance terms. It is clear from our findings, however, that performance benefits when applying music synchronously $(g=0.44)$ or asynchronously ( $g=0.31)$, in either an exercise or sport training context.

The absence of a differential effect on performance between synchronous and asynchronous music was inconsistent with claims previously made in the literature (e.g., Karageorghis \& Terry, 2009; Terry \& Karageorghis, 2011). Ever since Anshel and Marisi (1978) demonstrated the benefits of music synchronized to movement patterns, the received wisdom has been that synchronous music is superior to asynchronous music for endurance performance. This oft-made assertion was not supported by the present moderator analysis and shines a light on the need for more studies that make a direct comparison between synchronous and asynchronous music. Synchronous music studies are relatively rare, perhaps because of the extensive commitment of time and effort involved in conducting them (e.g., filming participants then matching musical beats to their movement rate; Simpson \& Karageorghis, 2006).

The moderation effect for physical activity intensity was nonsignificant but showed that performance benefits derived from music are generally stronger at low-to-moderate intensities than high intensities. This trend in the data can be related to earlierpresented theories suggesting that greater information processing capacity is available for external stimuli at low-to-moderate intensities (Rejeski, 1985; Tenenbaum, 2001). Music is perhaps more relevant at low-to-moderate intensities at which interoceptive cues do not interfere with its processing in the cerebral cortex (Ekkekakis, 2013). Moreover, there is less opportunity for the principles of entrainment to take hold at high intensities because of the overwhelming influence of physiological load on the body's main pulses.

Who selected the music did not have a moderating influence in terms of performance benefits. This is helpful from an applied perspective because in many exercise and sport contexts, the musical predilections of individual participants cannot be fully accounted for and so an instructor or coach would typically select the music with certain participant characteristics (e.g., age and gender) and the nature of the task in mind (Clark et al., 2016; Karageorghis, 2017).

Study quality did not moderate performance effects, with lowquality studies reporting similar effects to moderate-quality studies. The first point to draw from this is that loosening the reins of experimental control does not magnify the performance benefits of music. Although participants may be afforded some degree of choice, perhaps of musical genre, to ensure the scientific integrity of a study, it is often necessary that other salient musical qualities (e.g., tempo, inclusion or exclusion of lyrics, harmonic content, degree of familiarity) should be kept constant by the researcher(s), and the true purpose of music intervention(s) within the experimental protocol obscured until the postexperimental debriefing. Blinding in the traditional experimental sense is not possible with a music treatment but careful preparation in terms of what researchers say to participants and how they respond to questions can ameliorate the participants' ability to second-guess the expected outcome of experiments and behave or respond accordingly. Some studies in the present meta-analysis implemented little or no experimental control (e.g., Dillon, 1952; Hall \& Erickson, 1995).

Study setting (field vs. laboratory) did not significantly moderate the effect of music on performance, although the standardized 
effect for laboratory studies was slightly larger. In the case of level of participation, again no moderation effect emerged, although the effect for untrained participants was larger than that for their trained counterparts. There is a paucity of studies comparing trained vs. untrained participants on standardized tasks, leaving considerable scope for further work.

\section{Practical Application of the Findings}

Despite the relatively modest scale of the beneficial effects of music listening on outcome variables, each one may be of practical importance in exercise and sport environments and possibly beyond. The positive influence of music listening on affective valence highlights the utility of the present results for exercise and health professionals. Music interventions can be implemented to ameliorate negative affective experiences across the full gamut of physical activity intensities (e.g., Hutchinson \& Karageorghis, 2013; Karageorghis \& Jones, 2014). Such interventions may be particularly valuable among individuals who are initiating an exercise program following prolonged periods of inactivity. Research has shown that the negative affective responses experienced by exercise initiators represent a considerable barrier to continual or habitual participation in physical activity (Ekkekakis et al., 2013; Emerson \& Williams, 2015).

One relatively novel approach by which to use music is to apply the peak-end rule (Parfitt \& Hughes, 2009). Specifically, as demonstrated in some experimental studies (e.g., Lim, Atkinson, Karageorghis, \& Eubank, 2009), the differentiated use of music can have a potent effect because this approach enables practitioners or individual exercisers to place the musical stimulus precisely where its effects are likely to be most pronounced. Accordingly, rather than use music throughout the duration of an exercise session, it might be used for the last half or even last third when affective decline is most likely to occur (Ekkekakis \& Acevedo, 2006). The peak-end rule can be capitalized upon by creating a more pleasurable conclusion to a workout through the differentiated use of music.

Although there were no differential effects on performance for synchronous vs. asynchronous music, exercisers looking to boost their performance or athletes keen to enhance their training regimens might consider the application of auditory-motor synchronization, in light of performance benefits reported among the recreationally active (e.g., Bacon et al., 2012; Karageorghis et al., 2009) and the highly trained (e.g., Terry, Karageorghis, et al., 2012). Nonetheless, exercisers and athletes may need some training in the extraction of a musical beat to capitalize on the potential benefits of auditory-motor synchronization. In particular, some musical forms (e.g., hip-hop) are complex when it comes to beat extraction due to the common use of polyrhythms, wherein two or more rhythmic patterns are interwoven.

There is some qualitative evidence for the notion of shared affective motion experience (SAME; Molnar-Szakacs \& Overy, 2006; Overy, 2012), wherein exercisers or athletes sense the rhythm through others moving in time in their vicinity and enjoy the sensation of functioning as a unit (cf. spontaneous communitas; Turner, 2012). Exercise and sport professionals can take advantage of this concept to augment the experiences of those in their charge. For example, activities that are commonly conducted in a group setting, such as stretching, circuit training, and warm-down, can easily be coordinated with musical accompaniment. This adds to the sense of fun, enjoyment, and camaraderie, and thus promotes important facets of intrinsically motivated behavior (Nielsen et al., 2014; Ryan \& Deci, 2000, 2017). The enduring popularity of group exercise-to-music classes (e.g., Aquarobics, Boxercise, and Zumba) bears testament to this phenomenon.

In studies where participants selected their own music to accompany physical tests, close analysis revealed that some participants made appropriate choices for the activity in which they were engaged (e.g., Boutcher \& Trenske, 1990; Stork et al., 2015), whereas others apparently did not (e.g., Annesi, 2001; Nikbakhsh $\&$ Zafari, 2012). A general methodological limitation among studies that used self-selected music is that participants received little or no guidance in how to select appropriate music for the situation or task under consideration and therefore the psycho-acoustic properties of music differed markedly across participants (e.g., Bartolomei, Di Michele, \& Merni, 2015; Miller \& Donohue, 2003). Moreover, as previously highlighted, there is a greater likelihood for the emergence of Hawthorne and experimenter effects in studies where self-selected music is used (see, e.g., Chanda \& Levitin, 2013; Karageorghis \& Priest, 2012b).

Briefly revisiting the issue of promoting physical activity for its multiple health benefits, previous systematic reviews of the extant literature have highlighted the magnitude of the challenge (Conn, Valentine, \& Cooper, 2002; van Sluijs, McMinn, \& Griffin, 2007). For example, interventions designed to promote physical activity among older adults tend to have limited effectiveness, typically reporting small effects (Conn et al., 2002; Ruscello et al., 2014). Similarly, interventions to promote higher levels of physical activity among children and adolescents often show limited success, and those that are effective typically include multiple components (van Sluijs et al., 2007). The significant benefits of music identified in the present meta-analytic review suggest that the addition of music to augment other elements of a health promotion strategy may have the potential to enhance the efficacy of such strategies in the longer term (see Clark et al., 2012).

Our findings point to several potential applications of music in the sporting domain. In terms of the precompetition phase, it is clear that music can provide a small beneficial influence across the outcome variable set. Music can be used to modulate affect to a desirable valence, promote specific emotional responses, and regulate psychomotor arousal level. In the training environment, athletes may use music to reduce RPE even at relatively high work intensities (e.g., Terry, Karageorghis, et al., 2012). Both synchronous and asynchronous music applications have been associated with efficiency gains in repetitive motor tasks (e.g., Bacon et al., 2012; Szmedra \& Bacharach, 1998), but consideration of individual movement patterns such as stride rate, is advantageous for the application of synchronous music (e.g., Simpson \& Karageorghis, 2006). The use of recuperative music is relatively untapped in sport, leaving considerable scope for the structured use of music in both active and static recovery phases (e.g., Tan, Tengah, Nee, \& Fredericks, 2014).

\section{General Limitations}

To reduce the potential for selection bias, systematic and comprehensive search techniques were used to locate studies, although the possibility remains that search procedures may have failed to 
identify every salient investigation. The decision to exclude studies published in languages other than English is acknowledged as a minor limitation. Another limitation of the current meta-analysis, in common with all meta-analytic reviews, lies in the overall quality of the included studies. Using the Cochrane Collaboration tool (Higgins et al., 2011), all studies included in the present meta-analysis were rated in the low-to-moderate quality range. Given that it is not possible to blind participants to the presence or absence of a music intervention, there is no scope for double-blind, placebo-controlled designs, which is an inherent limitation of this particular research area as well as many other areas of psychology (e.g., Sedlmeier et al., 2012; Webb, Miles, \& Sheeran, 2012).

\section{Implications for Future Research}

Part of the rationale for this meta-analytic review was predicated on the possibility that music may increase adherence to physical activity. To date, very few studies have explicitly investigated this link, although some supportive results have emerged. For example, music enhanced adherence to a physical rehabilitation exercise program with elderly persons (Johnson, Otto, \& Clair, 2001), enhanced cardiovascular outcomes among a group of previously sedentary adults (Madison et al., 2013), and enhanced adherence to a physical activity-based weight loss program among obese women (Hradil, 2007). Further, in their systematic review of 20 studies, Ziv and Lidor (2011) showed that the addition of music to physical activity programs increased adherence in clinical populations and the elderly. Similarly, the Clark et al. (2012) metaanalysis concluded that "older adults who listen to recorded commercial music during exercise programs over several weeks may experience cumulative benefits with increased capacity to perform physical activity" (p. 717). Encouragingly, given that enhanced affective responses to music were the most robust finding in our meta-analysis, researchers have confirmed the mediating role of exercise-related affect in determining physical activity behaviors (Williams, Rhodes, \& Conner, 2018).

It is hoped that researchers will embrace the challenge of investigating ways to use music to enhance adherence to physical activity with a view to augmenting the physiological and psychological benefits that the public might derive (e.g., Saxena, Van Ommeren, Tang, \& Armstrong, 2005). Finding ways to buck the reliable trend that $40 \%$ to $65 \%$ of exercisers initiating new programs will discontinue them within the first 3-6 months (Dishman, 1988) has proven a substantial and perpetual challenge for physical activity and public health professionals. Given its demonstrated benefits, the inclusion of music in physical activity programs would appear to offer a reasonable chance of reducing dropout rate. Specific challenges lie in finding ways to use music that addresses some of the difficulties people face in their efforts to adhere to physical activity programs, such as using it to enhance exercise-related affect (e.g., Jones et al., 2014), reduce ratings of perceived exertion (e.g., Szmedra \& Bacharach, 1998), promote feelings of affiliation with other exercisers (e.g., Overy, 2012), and give exercisers a sense of autonomy by involving them in the music-selection process (e.g., Dwyer, 1995).

Given that engaging the general populous in health-related behaviors is one of the biggest challenges of the modern age, the potential for applying music in this context using a variety of physical activity modalities should be explored further. For exam- ple, dance-related programs have been shown to be efficacious in increasing physical activity levels in varying subgroups of the population (e.g., Beaulac, Kristjansson, \& Calhoun, 2011; Romero, 2012). Also, walking programs that apply synchronous music are an inexpensive and widely accessible form of physical activity, for which there is a growing body of empirical support (e.g., Franěk et al., 2014; Leman et al., 2013). Moreover, new technologies such as underwater mp3 players have created possibilities for music listening during swimming and other water-based activities, for which supportive scientific evidence has begun to accrue (e.g., Karageorghis et al., 2013; Tate et al., 2012). Considering that swimming reduces the load on weight-bearing joints and promotes cardiovascular fitness, it is particularly worthy of promotion by public health professionals.

Future research will proceed in several directions and be driven by a range of practical, methodological, and theoretical questions. From a practical perspective, one possible direction is to devote further attention to the combination of music with other stimuli that are typically encountered in physical activity settings, such as video. For example, despite previous studies (e.g., Jones et al., 2014), it is not yet known whether viewing music videos is superior to viewing music with incongruent visual stimuli (e.g., news or film channels), in terms of psychological responses. It is noteworthy that the combination of music and video has been popular in the health and fitness industry for over 20 years, yet research in exercise psychology has lagged behind what has occurred in practice. An exercise modality that has emerged recently involves exercise programs delivered via smartphones or tablets that combine verbal instruction with animated images and music (e.g., www.fitnessbuddyapp.com). This is an inexpensive form of exercise that people can complete at home in their own time.

Another unanswered question relates to possible differences between music delivery methods that vary in the extent of immersion provided for the listener (e.g., quadraphonic sound systems vs. personal music players or TV screens vs. virtual-reality headsets). Research into the combination of music with virtual-reality mediated exercise is at a nascent stage, but there is encouraging initial evidence, at least in terms of acute, if not chronic effects (e.g., Bird, Karageorghis, Baker, \& Brookes, 2019; Jones \& Ekkekakis, 2019). Also, further research is needed to compare the effects of self-selected vs. experimenter-selected music and how manipulation of a range of music factors (e.g., tempo, rhythm, volume, mode [major vs. minor harmony]) influences outcome variables of interest.

Our results provide strong evidence that music across the full tempo spectrum enhances affective valence and that musicinduced reductions in perceived exertion occur at both low-tomoderate and high exercise intensities. Researchers should continue to evaluate the degree to which music can enhance exerciserelated affect and reduce perceived exertion beyond the ventilatory threshold. The data in the present meta-analysis did not allow for such a precise assessment of the work intensity-music benefits relationship because of considerable variation in how intensity was set. A technical side-note is that researchers are advised to set work intensity relative to ventilatory threshold rather than use more traditional heart rate-based approaches, such as the popular Karvonen formula (Karvonen, Kentala, \& Mustala, 1957), which leads to unstandardized work intensities across participants (see Lim et al., 2014 for a discussion). 
An area of research with potential for significant expansion is the recuperative effects of music following exercise, training, and competition (e.g., Karageorghis, Bruce, et al., 2018). This application pertains particularly to those who engage in high-intensity activity, typical of many sporting pursuits, who may experience postexercise symptoms such as disturbed mood (Byrnes et al., 1985; Steptoe \& Bolton, 1988) and delayed onset muscle soreness (DOMS; Cheung, Hume, \& Maxwell, 2003) caused by microtrauma to muscle fibers. Minett and Duffield (2014) recently emphasized that postexercise recovery strategies have overwhelmingly focused on the regeneration of muscle physiology via strategies such as massage, stretching, and ice baths, but largely ignored the role of the central nervous system in the recovery process. Given the propensity of music to exert a sedative influence on the central nervous system, as well as to stimulate it (Chanda \& Levitin, 2013; Juslin, 2013), there is scope to examine the efficacy of relaxing music to enhance both the speed and quality of recovery.

There is a growing body of evidence supporting the use of recuperative or posttask music (e.g., Eliakim, Bodner, Meckel, Nemet, \& Eliakim, 2013; Savitha, Sejil, Rao, Roshan, \& Roshan, 2013), although methodological rigor has been questionable in some studies, and hence a program of systematic work is needed to drive this area forward and eventually inform evidence-based practice. Specific improvements that need to be made to studies examining the recuperative effects of music include combining both active and static recovery in study designs; to date, studies have tended to examine either one or the other of these recovery phases (e.g., Eliakim, Bodner, Eliakim, Nemet, \& Meckel, 2012; Savitha et al., 2013). Also, standardizing work intensity across participants (see Lim et al., 2014) and using measures sensitive to the rate of postexercise recovery (e.g., affective valence and salivary cortisol; see Tan et al., 2014) will serve to enhance the quality of the evidence base. Although standardized methods for assessing the motivational qualities of music in the domain of exercise and sport already exist (Karageorghis et al., 1999; Karageorghis, Priest, Terry, Chatzisarantis, \& Lane, 2006), there is currently no equivalent method for assessing the sedative qualities of music. Such a development would expedite the line of research that addresses the recuperative effects of music.

From a methodological standpoint, it is important to establish whether relatively high-intensity physical activity (close to ventilatory threshold) that is associated with significant cardiorespiratory benefits is rendered more appealing by music-related interventions and thus causes exercise participants to adhere for longer or to exercise habitually (Jones et al., 2014). Such research would have wide-reaching public health implications given the sharp rise in sedentary behavior and the concomitant diseases seen in developed countries over the last 20 years (see Ng et al., 2014). From a theoretical standpoint, future studies should further address the mechanisms that underlie music effects (e.g., the notion of entrainment). One approach would be to examine context-specific brain responses to music during varied physical activities via the use of noninvasive methods that are resistant to movement artifacts, such as functional near-infrared spectroscopy (Bigliassi, Barreto-Silva, Kanthack, \& Altimari, 2014; Ekkekakis, 2009). Another approach would entail further assessment of the influence of auditory-motor synchronization on metabolic efficiency using online respiratory analysis (Bacon et al., 2012) and to couple this with biomechanical indices of efficiency such as movement sensors to assess the regularity of the kinetic chain (Franěk et al., 2014; Leman et al., 2013). Such work would lead to mechanistic models that will supplement the metatheory and heuristic models that have appeared in this literature during the last decade (Clark et al., 2016; Karageorghis, 2016).

\section{Conclusions}

Overall, given the summative evidence in the research literature supporting music listening for exercise and sport across a range of outcome variables, it is reasonable to conclude that music has the capacity to provide significant positive effects for exercisers and athletes, particularly in the areas of enhanced affective responses and improved physical performance, but also in terms of reduced perceived exertion and more efficient oxygen utilization. Such effects are, however, by no means inevitable.

It is important to guard against the sort of wild extrapolations that followed in the wake of research showing that listening to a Mozart sonata was associated with enhancement of spatialtemporal reasoning as measured by the Stanford-Binet IQ test (Rauscher, Shaw, \& Ky, 1993). Among other outcomes, those findings resulted in Georgia setting aside a sizable annual budget in 1998 to fund the distribution of a classical music CD for every child in the state. A subsequent meta-analysis of the so-called Mozart effect demonstrated that any cognitive enhancement was small, short-lived, and did not signal any permanent change in general reasoning ability or IQ (Chabris, 1999). Although the present results represent a robust evidence base, it is important to bear in mind that the benefits of listening to music before or during physical activity are not guaranteed. For example, although pretask music is in common use by athletes, many of whom attest to its benefits (Bishop et al., 2007; Laukka \& Quick, 2013), our results showed that benefits to performance are likely to be small, although perhaps still meaningful.

Indeed, almost all benefits associated with music listening in exercise and sport are likely to be small in magnitude and may be restricted to feeling better and perceiving lower exertion, although the potential for genuine improvements to physiological efficiency and physical performance remains a possibility, and we recognize that any gains of that nature may prove to be extremely valuable for athletes involved in activities where the margins of success and failure can be extremely fine. A clear target for practitioners is to apply music-related interventions to the enhancement of affect and enjoyment during exercise with a view to enhancing adherence among the previously inactive. The central challenge for researchers and practitioners is no longer to speculate over whether music has the potential to provide benefits for exercisers and athletes, because clearly it does, but instead to clarify ways by which to use it optimally.

\section{References}

References marked with an asterisk indicate studies included in the meta-analysis.

*Almeida, F. A. M., Nunes, R. F. H., Ferreira, S. S., Krinski, K., Elsangedy, H. M., Buzzachera, C. F., . . . da Silva, S. G. (2015). Effects of musical tempo on physiological, affective, and perceptual variables and performance of self-selected walking pace. Journal of Physical Therapy Science, 27, 1709-1712. 
*Almeida, F. A. M., Nunes, R. F. H., Santos, B. V., Elsangedy, H. M., Krinski, K., Buzzachera, C. F., . . . da Silva, S. G. (2011). Effects of musical rhythm on psychophysiological responses and pacing strategy during treadmill walking at a self-selected pace [Abstract]. Medicine \& Science in Sports \& Exercise, 43, S20. http://dx.doi.org/10.1249/01 .MSS.0000402727.10536.7f

*Aloui, A., Briki, W., Baklouti, H., Chtourou, H., Driss, T., Chaouachi, A., . . Souissi, N. (2015). Listening to music during warming-up counteracts the negative effects of Ramadan observance on short-term maximal performance. PLOS ONE, 10, e0136400. http://dx.doi.org/10.1371/ journal.pone. 0136400

*Annesi, J. J. (2001). Effects of music, television, and a combination entertainment system on distraction, exercise adherence, and physical output in adults. Canadian Journal of Behavioural Science/Revue canadienne des sciences du comportement, 33, 193-202. http://dx.doi.org/10 $.1037 / \mathrm{h} 0087141$

*Anshel, M. H., \& Marisi, D. (1978). Effect of music and rhythm on physical performance. Research Quarterly, 49, 109-113.

*Arazi, H., Asadi, A., \& Purabed, M. (2015). Physiological and psychophysical responses to listening to music during warm-up and circuit-type resistance exercise in strength trained men. Journal of Sports Medicine, 2015, 389831. http://dx.doi.org/10.1155/2015/389831

*Arazi, H., Ghanbari, E., Zarabi, L., \& Rafati, F. (2017). The effect of fast, light and favorite music on physiological function and physical performance of the male athlete students. Central European Journal of Sport Sciences and Medicine, 17, 33-40. http://dx.doi.org/10.18276/cej.2017 .1-04

Assink, M., \& Wibbelink, C. J. M. (2016). Fitting three-level meta-analytic models in R: A step-by-step tutorial. The Quantitative Methods for Psychology, 12, 154-174. http://dx.doi.org/10.20982/tqmp.12.3.p154

*Atan, T. (2013). Effect of music on anaerobic exercise performance. Biology of Sport, 30, 35-39. http://dx.doi.org/10.5604/20831862 .1029819

*Atkinson, G., Wilson, D., \& Eubank, M. (2004). Effects of music on work-rate distribution during a cycling time trial. International Journal of Sports Medicine, 25, 611-615. http://dx.doi.org/10.1055/s-2004815715

*Aweau, J., \& Redus, B. (2015). The effects of motivational music on a 1.5 mile running time trial [Abstract]. Medicine \& Science in Sports \& Exercise, 47, 781. http://dx.doi.org/10.1249/01.mss.0000478868 .77803 .74

*Aweau, J., Redus, B., \& Cone, T. (2015). Effects of motivational music on perceived exertion in runners [Abstract]. Research Quarterly for Exercise and Sport, 86, A23. Retrieved from http://www.tandfonline.com/ doi/full/10.1080/02701367.2015.1049504

Ayres, L. P. (1911). The influence of music on speed in the six day bicycle race. American Physical Education Review, 16, 321-324. http://dx.doi .org/10.1080/23267224.1911.10651270

*Azam, K., Zarch, E. E., \& Zakerian, S. A. (2016). Investigate the effects of Iranian traditional music and western classical music on physical performance, the normal Profile of Mood States and rate of perceived exertion. International Journal of Health Studies, 2, 14-20. Retrieved from http://journals.research.ac.ir/files/site1/rds_journals/1805/article1805-377238.pdf

*Bacon, C. J., \& Hookway, S. (2003). The effect of musical selections on submaximal exercise parameters and self-selected exercise intensity in aerobics participants [Abstract]. Journal of Sports Sciences, 21, 259260.

Bacon, C. J., Myers, T. R., \& Karageorghis, C. I. (2012). Effect of music-movement synchrony on exercise oxygen consumption. The Journal of Sports Medicine and Physical Fitness, 52, 359-365. http://www .minervamedica.it/en/journals/sports-med-physical-fitness/archive.php

Baker, J., Côté, J., \& Deakin, J. (2005). Cognitive characteristics of expert, middle of the pack, and back of the pack ultra-endurance triathletes.
Psychology of Sport and Exercise, 6, 551-558. http://dx.doi.org/10 .1016/j.psychsport.2004.04.005

*Barney, D., \& Prusak, K. A. (2015). Effects of music on physical activity rates of elementary physical education students. Physical Educator, 72, 236-244. Retrieved from https://eric.ed.gov/?id=EJ1059809

*Bartolomei, S., Di Michele, R., \& Merni, F. (2015). Effects of selfselected music on maximal bench press strength and strength endurance. Perceptual and Motor Skills, 120, 714-721. http://dx.doi.org/10.2466/ 06.30.PMS.120v19x9

Barwood, M. J., Weston, N. J. V., Thelwell, R., \& Page, J. (2009). A motivational music and video intervention improves high-intensity exercise performance. Journal of Sports Science \& Medicine, 8, 435-442. http://www.jssm.org/vol8/n3/17/v8n3-17text.php

Beaulac, J., Kristjansson, E., \& Calhoun, M. (2011). 'Bigger than hiphop?' Impact of a community-based physical activity program on youth living in a disadvantaged neighborhood in Canada. Journal of Youth Studies, 14, 961-974. http://dx.doi.org/10.1080/13676261.2011.616488

Becker, B. J. (1988). Synthesizing standardized mean-change measures. British Journal of Mathematical and Statistical Psychology, 41, 257278. http://dx.doi.org/10.1111/j.2044-8317.1988.tb00901.x

*Becker, N., Brett, S., Chambliss, C., Crowers, K., Haring, P., Marsh, C., \& Montemayor, R. (1994). Mellow and frenetic antecedent music during athletic performance of children, adults, and seniors. Perceptual and Motor Skills, 79, 1043-1046. http://dx.doi.org/10.2466/pms.1994.79.2 .1043

*Becker, N., Chambliss, C., Marsh, C., \& Montemayor, R. (1995). Effects of mellow and frenetic music and stimulating and relaxing scents on walking by seniors. Perceptual and Motor Skills, 80, 411-415. http:// dx.doi.org/10.2466/pms.1995.80.2.411

*Beckett, A. (1990). The effects of music on exercise as determined by physiological recovery heart rates and distance. Journal of Music Therapy, 27, 126-136. http://dx.doi.org/10.1093/jmt/27.3.126

Beedie, C. J., Terry, P. C., \& Lane, A. M. (2005). Distinctions between emotion and mood. Cognition and Emotion, 19, 847-878. http://dx.doi .org/10.1080/02699930541000057

*Bell, D., Dominquez, I., Fijalka, A., Wallace, B., Woodworth, K., Zimney, M., \& McKenzie, J. (2016). Effects of self-selected, varying tempo music on performance and perceived exertion in collegiate rowers [Abstract]. International Journal of Exercise Science: Conference Proceedings, 8, 10. Retrieved from http://digitalcommons.wku.edu/ijesab/vol8/ iss $4 / 10$

*Benson, B. A., Cutrufello, P. T., \& Landram, M. J. (2017). The effects of self-selected music on exercise performance [Abstract]. International Journal of Exercise Science: Conference Proceedings, 9, 10. Retrieved from https://digitalcommons.wku.edu/ijesab/vol9/iss5/10

Bernardi, L., Porta, C., Casucci, G., Balsamo, R., Bernardi, N. F., Fogari, R., \& Sleight, P. (2009). Dynamic interactions between musical, cardiovascular, and cerebral rhythms in humans. Circulation, 119, 3171-3180. http://dx.doi.org/10.1161/CIRCULATIONAHA.108.806174

*Bharani, A., Sahu, A., \& Mathew, V. (2004). Effect of passive distraction on treadmill exercise test performance in healthy males using music. International Journal of Cardiology, 97, 305-306. http://dx.doi.org/10 .1016/j.ijcard.2003.05.048

Biagini, M. S. (2011). Effects of self-selected music on bench press, vertical jump and squat jump performance (Doctoral dissertation). Retrieved from ProQuest Dissertations and Theses Database. (UMI No. 1493258)

"Biagini, M. S., Brown, L. E., Coburn, J. W., Judelson, D. A., Statler, T. A., Bottaro, M., . . Longo, N. A. (2012). Effects of self-selected music on strength, explosiveness, and mood. Journal of Strength and Conditioning Research, 26, 1934-1938. http://dx.doi.org/10.1519/JSC .0b013e318237e7b3

Bigliassi, M., Barreto-Silva, V., Kanthack, T. F. D., \& Altimari, L. R. (2014). Music and cortical blood flow: A functional near-infrared spec- 
troscopy (fNIRS) study. Psychology \& Neuroscience, 7, 545-550. http:// dx.doi.org/10.3922/j.psns.2014.4.13

*Bigliassi, M., Dantas, J. L., Carneiro, J. G., Smirmaul, B. P. C., \& Altimari, L. R. (2012). Influence of music and its moments of application on performance and psychophysiological parameters during a $5 \mathrm{~km}$ time trial. Revista Andaluza de Medicina del Deporte, 5, 83-90. http:// dx.doi.org/10.1016/S1888-7546(12)70013-8

*Bigliassi, M., Karageorghis, C. I., Nowicky, A. V., Orgs, G., \& Wright, M. J. (2016). Cerebral mechanisms underlying the effects of music during a fatiguing isometric ankle-dorsiflexion task. Psychophysiology, 53, 1472-1483. http://dx.doi.org/10.1111/psyp.12693

"Bigliassi, M., Karageorghis, C. I., Wright, M. J., Orgs, G., \& Nowicky, A. V. (2017). Effects of auditory stimuli on electrical activity in the brain during cycle ergometry. Physiology \& Behavior, 177, 135-147. http:// dx.doi.org/10.1016/j.physbeh.2017.04.023

*Bigliassi, M., León-Domínguez, U., Buzzachera, C. F., Barreto-Silva, V., \& Altimari, L. R. (2015). How does music aid $5 \mathrm{~km}$ of running? Journal of Strength and Conditioning Research, 29, 305-314. http://dx.doi.org/ 10.1519/JSC.0000000000000627

Bigliassi, M., Peruzollo, A. S., Kanthack, T. F. D., da Silva, V. B., Pezarat-Correia, P., \& Atimari, L. R. (2014). Effects of a sensory strategy in an isometric muscular endurance task. Revista Andaluza de Medicina del Deporte, 7, 55-59. http://dx.doi.org/10.1016/S18887546(14)70062-0

"Bird, J. M., Hall, J., Arnold, R., Karageorghis, C. I., \& Hussein, A. (2016). Effects of music and music-video on core affect during exercise at the lactate threshold. Psychology of Music, 44, 1471-1487. http://dx.doi.org/ 10.1177/0305735616637909

Bird, J. M., Karageorghis, C. I., Baker, S. J., \& Brookes, D. A. (2019). Effects of music, video, and 360-degree video on cycle ergometer exercise at the ventilatory threshold. Scandinavian Journal of Medicine \& Science in Sports, 29, 1161-1173. http://dx.doi.org/10.1111/sms .13453

*Birnbaum, L., Boone, T., \& Huschle, B. (2009). Cardiovascular responses to music tempo during steady-state exercise. Journal of Exercise Physiology Online/American Society of Exercise Physiologists, 12, 50-57. Retrieved from https://www.asep.org/asep/asep/Birnbaum\%2012 $\% 281 \% 2950-56 . d o c$

Bishop, D. T., Karageorghis, C. I., \& Loizou, G. (2007). A grounded theory of young tennis players use of music to manipulate emotional state. Journal of Sport \& Exercise Psychology, 29, 584-607. Retrieved from http://journals.humankinetics.com/jsep. http://dx.doi.org/10.1123/jsep .29 .5 .584

Blumenstein, B., Bar-Eli, M., \& Tenenbaum, G. (1995). The augmenting role of biofeedback: Effects of autogenic, imagery and music training on physiological indices and athletic performance. Journal of Sports Sciences, 13, 343-354. http://dx.doi.org/10.1080/02640419508732248

*Bonnette, R., Smith, M. C., III, Spaniol, F., Ocker, L., \& Melrose, D. (2012). The effect of music listening on running performance and rating of perceived exertion of college students. The Sport Journal, 14, e440.

*Bood, R. J., Nijssen, M., van der Kamp, J., \& Roerdink, M. (2013). The power of auditory-motor synchronization in sports: Enhancing running performance by coupling cadence with the right beats. PLOS ONE, 8, e70758. http://dx.doi.org/10.1371/journal.pone.0070758

Borg, G. (1970). Perceived exertion as an indicator of somatic stress. Scandinavian Journal of Rehabilitation Medicine, 2, 92-98.

Borg, G. A. V. (1982). Psychophysical bases of perceived exertion. Medicine \& Science in Sports \& Exercise, 14, 377-381. http://dx.doi.org/10 .1249/00005768-198205000-00012

Borg, G. A. V. (1998). Borg's perceived exertion and pain scales. Champaign, IL: Human Kinetics.

*Boutcher, S. H., \& Trenske, M. (1990). The effects of sensory deprivation and music on perceived exertion and affect during exercise. Journal of
Sport \& Exercise Psychology, 12, 167-176. http://dx.doi.org/10.1123/ jsep.12.2.167

Bradt, J., \& Dileo, C. (2009). Music for stress and anxiety reduction in coronary heart disease patients. Cochrane Database of Systematic Reviews, 2, CD006577. http://dx.doi.org/10.1002/14651858.cd006577 .pub2

Brand, R., \& Ekkekakis, P. (2018). Affective-reflective theory of physical inactivity and exercise: Foundations and preliminary evidence. German Journal of Exercise and Sport Research, 48, 48-58. http://dx.doi.org/ 10.1007/s12662-017-0477-9

*Brohmer, R., \& Becker, C. (2006). Effects of music on Wingate performance. Journal of Undergraduate Kinesiology Research, 2, 49-55. Retrieved from http://digital.library.wisc.edu/1793/23609

*Brownley, K. A., McMurray, R. G., \& Hackney, A. C. (1995). Effects of music on physiological and affective responses to graded treadmill exercise in trained and untrained runners. International Journal of Psychophysiology, 19, 193-201. http://dx.doi.org/10.1016/0167-8760 (95)00007-F

*Brupbacher, G., Harder, J., Faude, O., Zahner, L., \& Donath, L. (2014). Music in CrossFit ${ }^{\circledR}$ - Influence on performance, physiological, and psychological parameters. Sports, 2, 14-23. http://dx.doi.org/10.3390/ sports 2010014

Burgess, E., Hassmén, P., \& Pumpa, K. L. (2017). Determinants of adherence to lifestyle intervention in adults with obesity: A systematic review. Clinical Obesity, 7, 123-135. http://dx.doi.org/10.1111/cob.12183

Byrnes, W. C., Clarkson, P. M., White, J. S., Hsieh, S. S., Frykman, P. N., \& Maughan, R. J. (1985). Delayed onset muscle soreness following repeated bouts of downhill running. Journal of Applied Physiology, 59, 710-715. http://dx.doi.org/10.1152/jappl.1985.59.3.710

"Carlier, M., Delevoye-Turrell, Y., \& the Fun2move consortium. (2017). Tolerance to exercise intensity modulates pleasure when exercising in music: The upsides of acoustic energy for High Tolerant individuals. PLoS ONE, 12, e0170383. http://dx.doi.org/10.1371/journal.pone .0170383

Chabris, C. F. (1999). Prelude or requiem for the 'Mozart effect'? Nature, 400, 826-827. http://dx.doi.org/10.1038/23608

Chanda, M. L., \& Levitin, D. J. (2013). The neurochemistry of music. Trends in Cognitive Sciences, 17, 179-193. http://dx.doi.org/10.1016/j .tics.2013.02.007

Chapados, C., \& Levitin, D. J. (2008). Cross-modal interactions in the experience of musical performances: Physiological correlates. Cognition, 108, 639-651. http://dx.doi.org/10.1016/j.cognition.2008.05.008

${ }^{*}$ Chatterjee, S., Ghosh, M. C., \& Ghosh, A. (2014). A study to explore the effects of varied tempo music on brisk walking performance. International Organisation of Scientific Research (IOSR) Journal of Sports and Physical Education, 1, 43-46. Retrieved from http://www.iosrjournals .org/iosr-jspe/papers/vol1-issue7/L0174346.pdf

Cheung, K., Hume, P., \& Maxwell, L. (2003). Delayed onset muscle soreness: Treatment strategies and performance factors. Sports Medicine, 33, 145-164. http://dx.doi.org/10.2165/00007256-20033302000005

*Chow, E. C., \& Etnier, J. L. (2017). Effects of music and video on perceived exertion during high-intensity exercise. Journal of Sport and Health Science, 6, 81-88. http://dx.doi.org/10.1016/j.jshs.2015.12.007

${ }^{*}$ Chtourou, H., Chaouachi, A., Hammouda, O., Chamari, K., \& Souissi, N. (2012). Listening to music affects diurnal variation in muscle power output. International Journal of Sports Medicine, 33, 43-47. http://dx .doi.org/10.1055/s-0031-1284398

*Chtourou, H., Hmide, C., \& Souissi, N. (2017). Effect of music on short-term maximal performance: Sprinters vs. long distance runners. Sport Sciences for Health, 13, 213-216. http://dx.doi.org/10.1007/ s11332-017-0357-6

${ }^{*}$ Chtourou, H., Jarraya, M., Aloui, A., Hammouda, O., \& Souissi, N. (2012). The effects of music during warm-up on anaerobic performances 
of young sprinters/Les effets de la musique lors de l'échauffement sur les performances anaérobies des jeunes sprinteurs. Science \& Sports, 27, e85-e88. http://dx.doi.org/10.1016/j.scispo.2012.02.006

Ciccomascolo, L. E. (1995). The effect of up-beat music on physiological and psychological variables among female basketball players performing exhaustive exercise (Doctoral dissertation). Retrieved from ProQuest Dissertations and Theses Database. (UMI No. 1359533)

Clark, I. N., Baker, F. A., Peiris, C. L., Shoebridge, G., \& Taylor, N. F. (2017). Participant-selected music and physical activity in older adults following cardiac rehabilitation: A randomized controlled trial. Clinical Rehabilitation, 31, 329-339. http://dx.doi.org/10.1177/026921551 6640864

Clark, I. N., Baker, F. A., \& Taylor, N. F. (2016). The modulating effects of music listening on health-related exercise and physical activity in adults: A systematic review and narrative synthesis. Nordic Journal of Music Therapy, 25, 76-104. http://dx.doi.org/10.1080/08098131.2015 .1008558

Clark, I. N., Taylor, N. F., \& Baker, F. (2012). Music interventions and physical activity in older adults: A systematic literature review and meta-analysis. Journal of Rehabilitation Medicine, 44, 710-719. http:// dx.doi.org/10.2340/16501977-1025

*Cohen, S. L., Paradis, C., \& LeMura, L. M. (2007). The effects of contingent-monetary reinforcement and music on exercise in college students. Journal of Sport Behavior, 30, 146-160. Retrieved from http:// www.southalabama.edu/colleges/artsandsci/psychology/Journal_of_ Sport_Behavior.html

"Cole, Z., \& Maeda, H. (2015). Effects of listening to preferential music on sex differences in endurance running performance. Perceptual and Motor Skills, 121, 390-398. http://dx.doi.org/10.2466/06.PMS.121c20x9

Conn, V. S., Valentine, J. C., \& Cooper, H. M. (2002). Interventions to increase physical activity among aging adults: A meta-analysis. Annals of Behavioral Medicine, 24, 190-200. http://dx.doi.org/10.1207/ S15324796ABM2403_04

Connon, H. (2011). The effect of differing types of music and music preference as a dissociative strategy on exercise performance and perceived exertion (Doctoral dissertation). Retrieved from ProQuest Dissertations and Theses database. (UMI No. MR89103)

*Copeland, B. L., \& Franks, B. D. (1991). Effects of types and intensities of background music on treadmill endurance. The Journal of Sports Medicine and Physical Fitness, 31, 100-103. Retrieved from http://www.minervamedica.it/en/journals/sports-med-physical-fitness/

"Corona, J. A. A., \& Vargas, L. F. A. (2017). Refining music tempo for an ergogenic effect of stationary cycling exercise. Pensar en Movimiento: Revista de Ciencias del Ejercicio y la Salud, 15, 28390. http://dx.doi .org/10.15517/pensarmov.v15i2.28390

Craig, A., Tran, Y., Wijesuriya, N., \& Nguyen, H. (2012). Regional brain wave activity changes associated with fatigue. Psychophysiology, 49, 574-582. http://dx.doi.org/10.1111/j.1469-8986.2011.01329.x

*Crust, L. (2004a). Carry-over effects of music in an isometric muscular endurance task. Perceptual and Motor Skills, 98, 985-991. http://dx.doi .org/10.2466/pms.98.3.985-991

*Crust, L. (2004b). Effects of familiar and unfamiliar asynchronous music on treadmill walking endurance. Perceptual and Motor Skills, 99, 361368. http://dx.doi.org/10.2466/PMS.99.5.361-368

Crust, L. (2008). Perceived importance of components of asynchronous music during circuit training. Journal of Sports Sciences, 26, 15471555. http://dx.doi.org/10.1080/02640410802315427

*Crust, L., \& Clough, P. J. (2006). The influence of rhythm and personality in the endurance response to motivational asynchronous music. Journal of Sports Sciences, 24, 187-195. http://dx.doi.org/10.1080/ 02640410500131514

*Curran, M. L., \& Terry, P. C. (2011). Effects of synchronous music use in ultra distance events [Abstract]. Journal of Science and Medicine in Sport, 14, S73. http://dx.doi.org/10.1016/j.jsams.2011.11.172
Dahl, S., Huron, D., Brod, G., \& Altenmüller, E. (2014). Preferred dance tempo: Does sex or body morphology influence how we groove? Journal of New Music Research, 43, 214-223. http://dx.doi.org/10.1080/ 09298215.2014.884144

*Davis, J. A., Miller, P. C., Cooper, K. L., Schmitt, E. E., Bixby, W. R., \& Hall, E. E. (2007). Relationships between self-efficacy and exercise performance during treadmill running [Abstract]. Medicine \& Science in Sports \& Exercise, 39, S411-S412. http://dx.doi.org/10.1249/01.mss .0000274625 .10184 .32

De Bourdeaudhuij, I., Crombez, G., Deforche, B., Vinaimont, F., Debode, P., \& Bouckaert, J. (2002). Effects of distraction on treadmill running time in severely obese children and adolescents. International Journal of Obesity, 26, 1023-1029. http://dx.doi.org/10.1038/sj.ijo.0802052

*Di Cagno, A., Iuliano, E., Fiorilli, G., Aquino, G., Giombini, A., Battaglia, C., . . Calcagno, G. (2015). Effects of rhythmical and extra-rhythmical qualities of music on heart rate during stationary bike activities. The Journal of Sports Medicine and Physical Fitness, 56, 1226-1231. Retrieved from https://europepmc.org/abstract/med/26022745

*Dillon, E. K. (1952). A study of the use of music as an aid in teaching swimming. Research Quarterly, 23, 1-8.

Dishman, R. K. (1988). Overview. In R. K. Dishman (Ed.), Exercise adherence: Its impact on public health (pp. 1-9). Champaign, IL: Human Kinetics.

Dos Santos Delabary, M., Komeroski, I. G., Monteiro, E. P., Costa, R. R., \& Haas, A. N. (2018). Effects of dance practice on functional mobility, motor symptoms and quality of life in people with Parkinson's disease: A systematic review with meta-analysis. Aging Clinical and Experimental Research, 30, 727-735. http://dx.doi.org/10.1007/s40520-0170836-2

Dwyer, J. J. M. (1995). Effect of perceived choice of music on exercise intrinsic motivation. Health Values: The Journal of Health Behavior, Education \& Promotion, 19, 18-26. Retrieved from http://psycnet.apa .org/psycinfo/1995-38358-001

*Dyer, B. J., \& McKune, A. J. (2013). Effects of music tempo on performance, psychological, and physiological variables during $20 \mathrm{~km}$ cycling in well-trained cyclists. Perceptual and Motor Skills, 117, 484-497. http://dx.doi.org/10.2466/29.22.PMS.117x24z8

*Dyrlund, A. K., \& Wininger, S. R. (2008). The effects of music preference and exercise intensity on psychological variables. Journal of Music Therapy, 45, 114-134. http://dx.doi.org/10.1093/jmt/45.2.114

*Edworthy, J., \& Waring, H. (2006). The effects of music tempo and loudness level on treadmill exercise. Ergonomics, 49, 1597-1610. http:// dx.doi.org/10.1080/00140130600899104

Egger, M., Davey Smith, G., Schneider, M., \& Minder, C. (1997). Bias in meta-analysis detected by a simple, graphical test. British Medical Journal, 315, 629-634. http://dx.doi.org/10.1136/bmj.315.7109.629

Ekkekakis, P. (2003). Pleasure and displeasure from the body: Perspectives from exercise. Cognition and Emotion, 17, 213-239. http://dx.doi.org/ 10.1080/02699930302292

Ekkekakis, P. (2009). Illuminating the black box: Investigating prefrontal cortical hemodynamics during exercise with near-infrared spectroscopy. Journal of Sport \& Exercise Psychology, 31, 505-553. http://journals .humankinetics.com/jsep. http://dx.doi.org/10.1123/jsep.31.4.505

Ekkekakis, P. (2013). The measurement of affect, mood, and emotion: A guide for health-behavioral research. New York, NY: Cambridge University Press. http://dx.doi.org/10.1017/CBO9780511820724

Ekkekakis, P., \& Acevedo, E. O. (Eds.). (2006). Affective responses to acute exercise: Toward a psychobiological dose-response model. Psychobiology of physical activity (pp. 91-109). Champaign, IL: Human Kinetics.

Ekkekakis, P., Hargreaves, E. A., \& Parfitt, G. (2013). Envisioning the next fifty years of research on the exercise-affect relationship. Psychology of Sport and Exercise, 14, 751-758. http://dx.doi.org/10.1016/j.psychsport .2013.04.007 
Ekkekakis, P., Hartman, M. E., \& Ladwig, M. A. (2020). Affective responses to exercise. In G. Tenenbaum \& R. C. Eklund (Eds.), Handbook of sport psychology (4th ed., pp. 233-253). New York, NY: Wiley.

Eliakim, M., Bodner, E., Eliakim, A., Nemet, D., \& Meckel, Y. (2012). Effect of motivational music on lactate levels during recovery from intense exercise. Journal of Strength and Conditioning Research, 26, 80-86. http://dx.doi.org/10.1519/JSC.0b013e31821d5f31

Eliakim, M., Bodner, E., Meckel, Y., Nemet, D., \& Eliakim, A. (2013). Effect of rhythm on the recovery from intense exercise. Journal of Strength and Conditioning Research, 27, 1019-1024. http://dx.doi.org/ 10.1519/JSC.0b013e318260b829

"Eliakim, M., Meckel, Y., Gotlieb, R., Nemet, D., \& Eliakim, A. (2012). Motivational music and repeated sprint ability in junior basketball players. Acta Kinesiologiae Universitatis Tartuenis, 18, 29-38. http://dx.doi .org/10.12697/akut.2012.18.04

*Eliakim, M., Meckel, Y., Nemet, D., \& Eliakim, A. (2007). The effect of music during warm-up on consecutive anaerobic performance in elite adolescent volleyball players. International Journal of Sports Medicine, 28, 321-325. http://dx.doi.org/10.1055/s-2006-924360

*Elliott, D. (2007). Music during exercise: Does tempo influence psychophysical responses? Philica.com (Article number 110). Retrieved from http://insight.cumbria.ac.uk/id/eprint/2755/

*Elliott, D., Carr, S., \& Orme, D. (2005). The effect of motivational music on sub-maximal exercise. European Journal of Sport Science, 5, $97-$ 106. http://dx.doi.org/10.1080/17461390500171310

*Elliott, D., Carr, S., \& Savage, D. (2004). Effects of motivational music on work output and affective responses during sub-maximal cycling of a standardized perceived intensity. Journal of Sport Behavior, 27, 134147. Retrieved from http://www.southalabama.edu/colleges/artsandsci/ psychology/Journal_of_Sport_Behavior.html

Elvers, P., \& Steffens, J. (2017). The sound of success: Investigating cognitive and behavioral effects of motivational music in sports. Frontiers in Psychology, 8, 2026. http://dx.doi.org/10.3389/fpsyg.2017 .02026

Emerson, J. A., \& Williams, D. M. (2015). The multifaceted relationship between physical activity and affect. Social and Personality Psychology Compass, 9, 419-433. http://dx.doi.org/10.1111/spc3.12190

"Fatouros, I., Chatzinikolaou, A., Jamurtas, A., Kallistratos, I., Baltzi, M., Douroudos, I., . . . Evangelou, A. (2005). The effects of self-selected music on physiological responses and performance during cardiovascular exercise [Abstract]. Medicine \& Science in Sports \& Exercise, 37, S106. Retrieved from http://www.acsm.org/access-public-information/ acsm-journals/medicine-science-in-sports-exercise

Ferguson, A. R., Carbonneau, M. R., \& Chambliss, C. (1994). Effects of positive and negative music on performance of a karate drill. Perceptual and Motor Skills, 78, 1217-1218. http://dx.doi.org/10.2466/pms.1994.78 $.3 c .1217$

Foster, C. E., Brennan, G., Matthews, A., McAdam, C., Fitzsimons, C., \& Mutrie, N. (2011). Recruiting participants to walking intervention studies: A systematic review. International Journal of Behavioral Nutrition and Physical Activity, 8, e137. http://dx.doi.org/10.1186/1479-5868-8137

Franěk, M., van Noorden, L., \& Režný, L. (2014). Tempo and walking speed with music in the urban context. Frontiers in Psychology, 5, e1361. http://dx.doi.org/10.3389/fpsyg.2014.01361

Fredrickson, B. L., \& Kahneman, D. (1993). Duration neglect in retrospective evaluations of affective episodes. Journal of Personality and Social Psychology, 65, 45-55. http://dx.doi.org/10.1037/0022-3514.65.1.45

*Gabana, N. T., Van Raalte, J., Hutchinson, J. C., Brewer, B. W., \& Petitpas, A. J. (2015). The effects of music and a coxswain on attentional focus, perceived exertion, motivation, and performance during a $1000 \mathrm{~m}$ ergometer rowing sprint. Journal of Applied Sport Psychology, 27, 288-300. http://dx.doi.org/10.1080/10413200.2014.993775
${ }^{*}$ Gallagher, P. M. (1996). No effect of music on performance and physiological parameters during a simulated race [Abstract]. Medicine \& Science in Sports \& Exercise, 28, S158. http://dx.doi.org/10.1097/ 00005768-199605001-00940

*Gatica, S. L. A., de Abreu, F. M., \& da Silveira, A. L. B. (2010). Effect of music on 400-m sprint running performance in healthy subjects [Abstract]. Medicine \& Science in Sports \& Exercise, 42, 26-27. http:// dx.doi.org/10.1249/01.MSS.0000389537.38423.77

*Ghaderi, M., Azarbaijani, M. A., Alinejad, H. A., Atashak, S., Shamsi, M. M., \& Ghaderi, D. (2012). Influence of music type listening on anaerobic performance and salivary cortisol in male athletes. Pedagogika, 12, 162-167.

*Ghaderi, M., Rahimi, R., \& Azarbayjani, M. A. (2009). The effect of motivational and relaxation music on aerobic performance, rating perceived exertion and salivary cortisol in athlete males. South African Journal for Research in Sport Physical Education and Recreation, 31, 29-38. Retrieved from http://www.journals.co.za/ej/ejour_sport.html

Gibbons, R. D., Hedeker, D. R., \& Davis, J. M. (1993). Estimation of effect size from a series of experiments involving paired comparisons. Journal of Educational Statistics, 18, 271-279. http://dx.doi.org/10.3102/ 10769986018003271

*Godwin, M. M., Hopson, R. T., Newman, C. K., \& Leszczak, T. J. (2014) The effect of music as a motivational tool on isokinetic concentric performance in college aged students. International Journal of Exercise Science, 7, 54-61. Retrieved from https://digitalcommons.wku.edu/ijes/ vol7/iss $1 / 7 /$

Goosey-Tolfrey, V. L., West, M., Lenton, J. P., \& Tolfrey, K. (2011). Influence of varied tempo music on wheelchair mechanical efficiency following 3-week practice. International Journal of Sports Medicine, 32, 126-131. http://dx.doi.org/10.1055/s-0030-1268439

Grahn, J. A., \& Brett, M. (2007). Rhythm and beat perception in motor areas of the brain. Journal of Cognitive Neuroscience, 19, 893-906. http://dx.doi.org/10.1162/jocn.2007.19.5.893

*Guillén, F., \& Ruiz-Alfonso, Z. (2015). Influence of music on physical performance, perceived exertion and motivation. Revista Internacional de Medicina y Ciencias de la Actividad Física y del Deporte, 60, 701-717. http://dx.doi.org/10.15366/rimcafd2015.60.006

*Gujjalal, R., Latha, G. M., \& Devi, S. U. (2017). Psychophysical effects of music in exercise. Scholars Journal of Applied Medical Sciences, 5 , 2301-2305

*Hagen, J., Foster, C., Rodríguez-Marroyo, J., de Koning, J. J., Mikat, R. P., Hendrix, C. R., \& Porcari, J. P. (2013). The effect of music on 10-km cycle time-trial performance. International Journal of Sports Physiology and Performance, 8, 104-106. http://dx.doi.org/10.1123/ ijspp.8.1.104

*Hall, K. G., \& Erickson, B. (1995). The effects of preparatory arousal on sixty-meter dash performance. Applied Research in Coaching and Athletics Annual, 10, 70-79. Retrieved from http://www.americanpress publishers.com/ARCAA.html

Hallett, R., \& Lamont, A. (2017). Music use in exercise: A questionnaire study. Media Psychology, 20, 658-684. http://dx.doi.org/10.1080/ 15213269.2016.1247716

*Haluk, K., Turchian, C., \& Adnan, C. (2009). Influence of music on Wingate anaerobic test performance. Ovidius University Annals, Series Physical Education \& Sport/Science, Movement \& Health, 9, 134-138. Retrieved from http://journalseeker.researchbib.com/?action=view JournalDetails\&issn $=12247359 \&$ uid $=\mathrm{r} 4 \mathrm{~d} 4 \mathrm{bb}$

Hardy, C. J., \& Rejeski, W. J. (1989). Not what, but how one feels: The measurement of affect during exercise. Journal of Sport \& Exercise Psychology, 11, 304-317. http://dx.doi.org/10.1123/jsep.11.3.304

Hedges, L. V. (1981). Distribution theory for Glass's estimator of effect size and related estimators. Journal of Educational Statistics, 6, 107128. http://dx.doi.org/10.3102/10769986006002107 
*Hefty, T., Minnie, B., Kim, H., Porter, N., \& McKenzie, J. (2017). The effects of self-selected music and performance and recovery during repeated Wingate tests [Abstract]. International Journal of Exercise Science: Conference Proceedings, 8, 74. Retrieved from http:// digitalcommons.wku.edu/ijesab/vol8/iss5/74

*Hepler, C., \& Kapke, R. (1996). Effect of music on cardiovascular performance during treadmill walking. IAHPERD Journal. Advance online publication. Retrieved from http://www.iahperd.org/textpages/ offerings/publications/journal.php

Higgins, E. T. (1997). Beyond pleasure and pain. American Psychologist, 52, 1280-1300. http://dx.doi.org/10.1037/0003-066X.52.12.1280

Higgins, J. P. T., Altman, D. G., Gøtzsche, P. C., Jüni, P., Moher, D., Oxman, A. D., . . . the Cochrane Bias Methods Group, \& the Cochrane Statistical Methods Group. (2011). The Cochrane Collaboration's tool for assessing risk of bias in randomised trials. British Medical Journal, 343, d5928. http://dx.doi.org/10.1136/bmj.d5928

Himberg, T. (2017). Entrainment and mutual adaptation in musical movement and dance. In M. Lesaffre, P.-J. Maes, \& M. Leman (Eds.), The Routledge companion to embodied music interaction (pp. 141-149). New York, NY: Routledge. http://dx.doi.org/10.4324/9781315 621364-16

Hirasaki, E., Moore, S. T., Raphan, T., \& Cohen, B. (1999). Effects of walking velocity on vertical head and body movements during locomotion. Experimental Brain Research, 127, 117-130. http://dx.doi.org/10 $.1007 / \mathrm{s} 002210050781$

Hradil, A. (2007). Effect of music on adherence to a comprehensive weight loss program for overweight to moderately obese women. Dissertation Abstracts International: Sciences and Engineering, 67, 4710. Retrieved from http://catalogue.nla.gov.au/Record/851068

Hutchinson, J. C., Jones, L., Vitti, S. N., Moore, A., Dalton, P. C., \& O'Neill, B. J. (2018). The influence of self-selected music on affectregulated exercise intensity and remembered pleasure during treadmill running. Sport, Exercise, and Performance Psychology, 7, 80-92. http:// dx.doi.org/10.1037/spy0000115

*Hutchinson, J. C., \& Karageorghis, C. I. (2013). Moderating influence of dominant attentional style and exercise intensity on responses to asynchronous music. Journal of Sport \& Exercise Psychology, 35, 625-643. http://dx.doi.org/10.1123/jsep.35.6.625

Hutchinson, J. C., Karageorghis, C. I., \& Black, J. D. (2017). The Diabeates Project: Perceptual, affective and psychophysiological effects of music and music-video in a clinical exercise setting. Canadian Journal of Diabetes, 41, 90-96. http://dx.doi.org/10.1016/j.jcjd.2016.07.009

"Hutchinson, J. C., Karageorghis, C. I., \& Jones, L. (2015). See hear: Psychological effects of music and music-video during treadmill running. Annals of Behavioral Medicine, 49, 199-211. http://dx.doi.org/10 .1007/s12160-014-9647-2

"Hutchinson, J., Sherman, T., Davis, L., Cawthon, D., Reeder, N., \& Tenenbaum, G. (2011). The influence of asynchronous motivational music on a supramaximal exercise bout. International Journal of Sport Psychology, 42, 135-148. Retrieved from http://www.ijsp-online.com/

*Jansen van Rensburg, L., Kroff, J., \& Terblanche, E. (2004). Does listening to music during warm-up improve 30 minute time trial performance? In V. Klissouras, S. Kellis, \& I. Mouratidis (Eds.), 2004 preOlympic congress: Sport science through the ages: Challenges in the new millenium (pp. 352-354). Thessaloniki, Greece: Aristotle University.

*Jarraya, M., Chtourou, H., Aloui, A., Hammouda, O., Chamari, K., Chaouachi, A., \& Souissi, N. (2012). The effects of music on highintensity short-term exercise in well-trained athletes. Asian Journal of Sports Medicine, 3, 233-238. http://dx.doi.org/10.5812/asjsm.34543

*Jia, T., Ogawa, Y., Miura, M., Ito, O., \& Kohzuki, M. (2016). Music attenuated a decrease in parasympathetic nervous system activity after exercise. PLoS ONE, 11, e0148648. http://dx.doi.org/10.1371/journal .pone. 0148648
Jing, L., \& Xudong, W. (2008). Evaluation on the effects of relaxing music on the recovery from aerobic exercise-induced fatigue. The Journal of Sports Medicine and Physical Fitness, 48, 102-106. Retrieved from http://www.minervamedica.it/en/journals/sports-med-physical-fitness/

Johnson, B. T., \& Huedo-Medina, T. B. (2013). Meta-analytic statistical inferences for continuous measure outcomes as a function of effect size metric and other assumptions. Rockville, MD: Agency for Healthcare Research and Quality. Retrieved from https://www.ncbi.nlm.nih.gov/ books/NBK140575/

Johnson, G., Otto, D., \& Clair, A. A. (2001). The effect of instrumental and vocal music on adherence to a physical rehabilitation exercise program with persons who are elderly. Journal of Music Therapy, 38, 82-96. http://dx.doi.org/10.1093/jmt/38.2.82

*Jones, J., Berstecher, M., Parks, A., Mullen, S., Brennan, K., Forlenza, S. \& Sanders, J. (2016). The effect of headphone versus room music on aerobic performance [Abstract]. International Journal of Exercise Science: Conference Proceedings, 9, 55. Retrieved from https:// digitalcommons.wku.edu/ijes/

Jones, L., \& Ekkekakis, P. (2019). Affect and prefrontal hemodynamics during exercise under immersive audiovisual stimulation: Improving the experience of exercise for overweight adults. Journal of Sport and Health Science, 8, 325-338. http://dx.doi.org/10.1016/j.jshs.2019.03 .003

*Jones, L., Karageorghis, C. I., \& Ekkekakis, P. (2014). Can high-intensity exercise be more pleasant?: Attentional dissociation using music and video. Journal of Sport \& Exercise Psychology, 36, 528-541. http://dx .doi.org/10.1123/jsep.2013-0251

Jones, L., Tiller, N. B., \& Karageorghis, C. I. (2017). Psychophysiological effects of music on acute recovery from high-intensity interval training. Physiology \& Behavior, 170, 106-114. http://dx.doi.org/10.1016/j physbeh.2016.12.017

Juslin, P. N. (2013). From everyday emotions to aesthetic emotions: Towards a unified theory of musical emotions. Physics of Life Reviews, 10, 235-266. http://dx.doi.org/10.1016/j.plrev.2013.05.008

Kämpfe, J., Sedlmeier, P., \& Renkewitz, F. (2011). The impact of background music on adult listeners: A meta-analysis. Psychology of Music, 39, 424-448. http://dx.doi.org/10.1177/0305735610376261

Karageorghis, C. I. (1992). The psychophysical effects of music in sport and exercise: A meta-analysis. (Unpublished master's thesis). United States Sports Academy, Daphne, AL

Karageorghis, C. I. (2016). The scientific application of music in exercise and sport: Towards a new theoretical model. In A. M. Lane (Ed.), Sport and exercise psychology (2nd ed., pp. 274-320). London, UK: Taylor \& Francis.

Karageorghis, C. I. (2017). Applying music in exercise and sport. Champaign, IL: Human Kinetics.

Karageorghis, C. I. (2020). Music-related interventions in sport and exercise. In G. Tenenbaum \& R. C. Eklund (Eds.), Handbook of sport psychology (4th ed., pp. 929-949). Hoboken, NJ: Wiley.

Karageorghis, C. I., Bigliassi, M., Tayara, K., Priest, D.-L., \& Bird, J. M (2018). A grounded theory of music use in the psychological preparation of academy soccer players. Sport, Exercise, and Performance Psychology, 7, 109-127. http://dx.doi.org/10.1037/spy0000110

Karageorghis, C. I., Bruce, A. C., Pottratz, S. T., Stevens, R. C., Bigliassi, M., \& Hamer, M. (2018). Psychological and psychophysiological effects of recuperative music post-exercise. Medicine \& Science in Sports \& Exercise, 50, 739-746. http://dx.doi.org/10.1249/MSS.0000000 000001497

*Karageorghis, C. I., Cheek, P., Simpson, S. D., \& Bigliassi, M. (2018) Interactive effects of music tempi and intensities on grip strength and subjective affect. Scandinavian Journal of Medicine \& Science in Sports, 28, 1166-1175. http://dx.doi.org/10.1111/sms.12979 
*Karageorghis, C. I., Drew, K. M., \& Terry, P. C. (1996). Effects of pretest stimulative and sedative music on grip strength. Perceptual and Motor Skills, 83, 1347-1352. http://dx.doi.org/10.2466/pms.1996.83.3f.1347

"Karageorghis, C. I., Hutchinson, J. C., Jones, L., Farmer, H. L., Ayhan, M. S., Wilson, R. C., . . Bailey, S. G. (2013). Psychological, psychophysical, and ergogenic effects of music in swimming. Psychology of Sport and Exercise, 14, 560-568. http://dx.doi.org/10.1016/j.psychsport .2013.01.009

"Karageorghis, C. I., \& Jones, J. (2000). Effects of synchronous and asynchronous music in cycle ergometry [Abstract]. Journal of Sports Sciences, 18, 16.

"Karageorghis, C. I., \& Jones, L. (2014). On the stability and relevance of the exercise heart rate-music-tempo preference relationship. Psychology of Sport and Exercise, 15, 299-310. http://dx.doi.org/10.1016/j .psychsport.2013.08.004

Karageorghis, C. I., Jones, L., Priest, D.-L., Akers, R. I., Clarke, A., Perry, J. M., . . . Lim, H. B. T. (2011). Revisiting the relationship between exercise heart rate and music tempo preference. Research Quarterly for Exercise and Sport, 82, 274-284. http://dx.doi.org/10.1080/02701367 .2011.10599755

Karageorghis, C., Jones, L., \& Stuart, D. P. (2008). Psychological effects of music tempi during exercise. International Journal of Sports Medicine, 29, 613-619. http://dx.doi.org/10.1055/s-2007-989266

*Karageorghis, C. I., \& Lee, J. (2001). Effects of motivational music and imagery on isometric muscular endurance. In A. Papaioannou, M. Goudas, \& Y. Theodorakis (Eds.), In the dawn of the new millennium: Proceedings of the International Society of Sport Psychology 10th World Congress (pp. 122-124). Thessaloniki, Greece: Christodoulidi Publications.

*Karageorghis, C. I., Mouzourides, D. A., Priest, D.-L., Sasso, T. A., Morrish, D. J., \& Walley, C. J. (2009). Psychophysical and ergogenic effects of synchronous music during treadmill walking. Journal of Sport \& Exercise Psychology, 31, 18-36. http://dx.doi.org/10.1123/jsep.31 .1 .18

Karageorghis, C. I., \& Priest, D.-L. (2012a). Music in the exercise domain: A review and synthesis (Part I). International Review of Sport and Exercise Psychology, 5, 44-66. http://dx.doi.org/10.1080/1750984X .2011 .631026

Karageorghis, C. I., \& Priest, D.-L. (2012b). Music in the exercise domain: A review and synthesis (Part II). International Review of Sport and Exercise Psychology, 5, 67-84. http://dx.doi.org/10.1080/1750984X .2011 .631027

Karageorghis, C. I., Priest, D.-L., Terry, P. C., Chatzisarantis, N. L., \& Lane, A. M. (2006). Redesign and initial validation of an instrument to assess the motivational qualities of music in exercise: The Brunel Music Rating Inventory-2. Journal of Sports Sciences, 24, 899-909. http://dx .doi.org/10.1080/02640410500298107

"Karageorghis, C. I., Priest, D.-L., Williams, L. S., Hirani, R. M., Lannon, K. M., \& Bates, B. J. (2010). Ergogenic and psychological effects of synchronous music during circuit-type exercise. Psychology of Sport and Exercise, 11, 551-559. http://dx.doi.org/10.1016/j.psychsport.2010.06 .004

Karageorghis, C. I., \& Terry, P. C. (1997). The psychophysical effects of music in sport and exercise: A review. Journal of Sport Behavior, 20, 54-68. Retrieved from http://www.cabdirect.org/abstracts/19971 804084.html

Karageorghis, C. I., \& Terry, P. C. (2009). The psychological, psychophysical, and ergogenic effects of music in sport: A review and synthesis. In A. J. Bateman \& J. R. Bale (Eds.), Sporting sounds: Relationships between sport and music (pp. 13-36). London, UK: Routledge.

Karageorghis, C. I., Terry, P. C., \& Lane, A. M. (1999). Development and initial validation of an instrument to assess the motivational qualities of music in exercise and sport: The Brunel Music Rating Inventory. Jour- nal of Sports Sciences, 17, 713-724. http://dx.doi.org/10.1080/ 026404199365579

Karvonen, M. J., Kentala, E., \& Mustala, O. (1957). The effects of training on heart rate; a longitudinal study. Annales Medicinae Experimentalis et Biologiae Fenniae, 35, 307-315.

*Kasi, H., \& Brooks, K. (2009). Effects of music and watching television during exercise on times of volitional fatigue and rates of perceived exertion [Abstract]. Medicine \& Science in Sports \& Exercise, 41, S451. http://dx.doi.org/10.1249/01.MSS.0000355923.45094.6f

*Kiel, T. J., Roth, E. A., Cheatham, C. C., Wilson, B. L., Bali, S. W., \& Appiah, J. E. (2008). The effect of auditory-motor synchronization on physiological responses and perceived exertion during treadmill running [Abstract]. Medicine \& Science in Sports \& Exercise, 40, S383. http:// dx.doi.org/10.1249/01.mss.0000322636.39076.3c

Laukka, P., \& Quick, L. (2013). Emotional and motivational uses of music in sports and exercise: A questionnaire study among athletes. Psychology of Music, 41, 198-215. http://dx.doi.org/10.1177/03057356 11422507

*Lee, S., \& Kimmerly, D. S. (2016). Influence of music on maximal self-paced running performance and passive post-exercise recovery rate. The Journal of Sports Medicine and Physical Fitness, 56, 39-48.

Leman, M., Moelants, D., Varewyck, M., Styns, F., van Noorden, L., \& Martens, J.-P. (2013). Activating and relaxing music entrains the speed of beat synchronized walking. PLOS ONE, 8, e67932. http://dx.doi.org/ 10.1371/journal.pone.0067932

Levitin, D. J. (2006). This is your brain on music: The science of a human obsession. New York, NY: Dutton Penguin.

"Liles, L., Dugan, K., Mallander, A., White, J., Krause, J., Taylor, L., . . Ballard, C. (2011). Perceived exertion: A comparative study using different forms of distraction during elliptical training [Abstract]. Journal of Strength and Conditioning Research, 26, S62-S63.

Lim, H. B. T., Atkinson, G., Karageorghis, C. I., \& Eubank, M. R. (2009). Effects of differentiated music on cycling time trial. International Journal of Sports Medicine, 30, 435-442. http://dx.doi.org/10.1055/s-00281112140

*Lim, H. B. T., Karageorghis, C. I., Romer, L. M., \& Bishop, D. T. (2014). Psychophysiological effects of synchronous versus asynchronous music during cycling. Medicine \& Science in Sports \& Exercise, 46, 407-413. http://dx.doi.org/10.1249/MSS.0b013e3182a6378c

"Lima-Silva, A. E., Silva-Cavalcante, M. D., Pires, F. O., Bertuzzi, R., Oliveira, R. S. F., \& Bishop, D. (2012). Listening to music in the first, but not the last $1.5 \mathrm{~km}$ of a $5-\mathrm{km}$ running trial alters pacing strategy and improves performance. International Journal of Sports Medicine, 33, 813-818. http://dx.doi.org/10.1055/s-0032-1311581

*Lin, J. H., \& Lu, F. J. H. (2013). Interactive effects of visual and auditory intervention on physical performance and perceived effort. Journal of Sports Science \& Medicine, 12, 388-393. Retrieved from http://www .jssm.org

"Loizou, G., \& Karageorghis, C. I. (2015). Effects of psychological priming, video, and music on anaerobic exercise performance. Scandinavian Journal of Medicine \& Science in Sports, 25, 909-920. http://dx.doi org/10.1111/sms.12391

Long, D. A. (1999). The influence of background music on exercise rate as graded by sit-ups (Doctoral dissertation). Available from ProQuest Dissertations and Theses database. (UMI No. 1353438)

*Lopes-Silva, J. P., Lima-Silva, A. E., Bertuzzi, R., \& Silva-Cavalcante, M. D. (2015). Influence of music on performance and psychophysiological responses during moderate-intensity exercise preceded by fatigue Physiology \& Behavior, 139, 274-280. http://dx.doi.org/10.1016/j .physbeh.2014.11.048

MacDougall, H. G., \& Moore, S. T. (2005). Marching to the beat of the same drummer: The spontaneous tempo of human locomotion. Journal of Applied Physiology, 99, 1164-1173. http://dx.doi.org/10.1152/ japplphysiol.00138.2005 
*MacEneaney, O. J., O’Gorman, D., Moran, K., Kerrane, J., Woods, C., . . . Moyna, N. M. (2004). The effect of preferred music on perception of effort and self-selected exercise intensity [Abstract]. Medicine \& Science in Sports \& Exercise, 36, S126. Retrieved from http://journals .lww.com/acsm-msse/pages/default.aspx

Madison, G., Paulin, J., \& Aasa, U. (2013). Physical and psychological effects from supervised aerobic music exercise. American Journal of Health Behavior, 37, 780-793. http://dx.doi.org/10.5993/AJHB.37.6.7

*Marin-Hernandez, J., \& Aragon-Vargas, L. F. (1999). Effect of sound intensity of music on perceived exertion during cycle exercise [Abstract]. Medicine \& Science in Sports \& Exercise, 31, S314. http://dx .doi.org/10.1097/00005768-199905001-01562

"McMordie, J. (2009). The effect of music loudness on anaerobic performance and muscular endurance [Abstract]. Medicine \& Science in Sports \& Exercise, 41, S257. http://dx.doi.org/10.1249/01.MSS.0000355339 .14943 .39

Mesagno, C., Marchant, D., \& Morris, T. (2009). Alleviating choking: The sounds of distraction. Journal of Applied Sport Psychology, 21, 131147. http://dx.doi.org/10.1080/10413200902795091

*Miller, A., \& Donohue, B. (2003). The development and controlled evaluation of athletic mental preparation strategies in high school distance runners. Journal of Applied Sport Psychology, 15, 321-334. http:// dx.doi.org/10.1080/714044200

Miller, M., Beach, V., Mangano, C., \& Vogel, R. A. (2008, November). Positive emotions and the endothelium: Does joyful music improve vascular health? Presented at the American Heart Association Scientific Sessions, New Orleans, LA.

*Miller, P. C., Bailey, E. K., Blakeslee, R. L., Hall, E. E., \& Bailey, S. P. (2006). The influence of various distraction stimuli on affective responses to cycle ergometry [Abstract]. Medicine \& Science in Sports \& Exercise, 38, S98. http://dx.doi.org/10.1249/00005768-20060500101333

*Miller, P. C., Hall, E. E., \& Bailey, E. K. (2016). The influence of various distraction stimuli on affective responses during recumbent cycle ergometry. Sports, 4, e21. http://dx.doi.org/10.3390/sports4020021

Minett, G. M., \& Duffield, R. (2014). Is recovery driven by central or peripheral factors? A role for the brain in recovery following intermittent-sprint exercise. Frontiers in Physiology, 5, e24. http://dx.doi .org/10.3389/fphys.2014.00024

Mithen, S. (2005). The singing Neanderthals: The origins of music, language, mind and body. London, UK: Weidenfeld \& Nicholson.

Moens, B., Muller, C., van Noorden, L., Franěk, M., Celie, B., Boone, J., ... Leman, M. (2014). Encouraging spontaneous synchronisation with D-Jogger, an adaptive music player that aligns movement and music. PLOS ONE, 9, e114234. http://dx.doi.org/10.1371/journal.pone.0114234

"Mohammadzadeh, H., Tartibiyan, B., \& Ahmadi, A. (2008). The effects of music on the perceived exertion rate and performance of trained and untrained individuals during progressive exercise. Facta Universitatis. Series: Physical Education and Sport, 6, 67-74. Retrieved from http:// facta.junis.ni.ac.rs/pe/pe.html

Moher, D., Liberati, A., Tetzlaff, J., Altman, D. G., \& the PRISMA Group. (2009). Preferred reporting items for systematic reviews and metaanalyses: The PRISMA statement. PLoS Medicine, 6, e1000097. http:// dx.doi.org/10.1371/journal.pmed.1000097

Molnar-Szakacs, I., \& Overy, K. (2006). Music and mirror neurons: From motion to 'e'motion. Social Cognitive and Affective Neuroscience, 1 , 235-241. http://dx.doi.org/10.1093/scan/ns1029

"Nakamura, P. M., Pereira, G., Papini, C. B., Nakamura, F. Y., \& Kokubun, E. (2010). Effects of preferred and nonpreferred music on continuous cycling exercise performance. Perceptual and Motor Skills, 110, 257-264. http://dx.doi.org/10.2466/pms.110.1.257-264

*Nethery, V. M. (2002). Competition between internal and external sources of information during exercise: Influence on RPE and the impact of the exercise load. The Journal of Sports Medicine and Physical Fitness, 42,
172-178. Retrieved from http://www.minervamedica.it/en/journals/sports-medphysical-fitness/index.php

Ng, M., Fleming, T., Robinson, M., Thomson, B., Graetz, N., Margono, C., Gakidou, E. (2014). Global, regional, and national prevalence of overweight and obesity in children and adults during 1980-2013: A systematic analysis for the Global Burden of Disease Study 2013. The Lancet, 384, 766-781. http://dx.doi.org/10.1016/S0140-6736(14) 60460-8

Nielsen, G., Wikman, J. M., Jensen, C. J., Schmidt, J. F., Gliemann, L., \& Andersen, T. R. (2014). Health promotion: The impact of beliefs of health benefits, social relations and enjoyment on exercise continuation. Scandinavian Journal of Medicine \& Science in Sports, 24, 66-75. http://dx.doi.org/10.1111/sms.12275

*Nikbakhsh, R., \& Zafari, A. (2012). The effect of music on affect at progressive cycling. European Journal of Experimental Biology, 2, 1395-1399. Retrieved from http://www.imedpub.com/articles/theeffect-of-music-on-affect-at-progressive-cycling.pdf

North, A. C., \& Hargreaves, D. J. (Eds.). (2008). Musical preference and taste. The social and applied psychology of music (pp. 75-142). Oxford, UK: Oxford University Press. http://dx.doi.org/10.1093/acprof:oso/ 9780198567424.003.0003

*Olson, R. L., Brush, C. J., O'Sullivan, D. J., \& Alderman, B. L. (2015). Psychophysiological and ergogenic effects of music in swimming. Comparative Exercise Physiology, 11, 79-87. http://dx.doi.org/10.3920/ CEP150003

Ooishi, Y., Mukai, H., Watanabe, K., Kawato, S., \& Kashino, M. (2017) Increase in salivary oxytocin and decrease in salivary cortisol after listening to relaxing slow-tempo and exciting fast-tempo music. PLoS ONE, 12, e0189075. http://dx.doi.org/10.1371/journal.pone.0189075

Overy, K. (2012). Making music in a group: Synchronization and shared experience. Annals of the New York Academy of Sciences, 1252, 65-68. http://dx.doi.org/10.1111/j.1749-6632.2012.06530.x

Parfitt, G., Alrumh, A., \& Rowlands, A. V. (2012). Affect-regulated exercise intensity: Does training at an intensity that feels 'good' improve physical health? Journal of Science and Medicine in Sport, 15, 548-553. http://dx.doi.org/10.1016/j.jsams.2012.01.005

Parfitt, G., \& Hughes, S. (2009). The exercise intensity-affect relationship: Evidence and implications for exercise behavior. Journal of Exercise Science and Fitness, 7, S34-S41. http://dx.doi.org/10.1016/S1728869X(09)60021-6

Patel, A. D. (2008). Music, language, and the brain. New York, NY: Oxford University Press.

Pereira, C. S., Teixeira, J., Figueiredo, P., Xavier, J., Castro, S. L., \& Brattico, E. (2011). Music and emotions in the brain: Familiarity matters. PLoS ONE, 6, e27241. http://dx.doi.org/10.1371/journal.pone .0027241

Phillips-Silver, J., \& Keller, P. E. (2012). Searching for roots of entrainment and joint action in early musical interactions. Frontiers in Human Neuroscience, 6, e26. http://dx.doi.org/10.3389/fnhum.2012.00026

*Potteiger, J. A., Schroeder, J. M., \& Goff, K. L. (2000). Influence of music on ratings of perceived exertion during 20 minutes of moderate intensity exercise. Perceptual and Motor Skills, 91, 848-854. http://dx.doi.org/ 10.2466/pms.2000.91.3.848

*Pujol, T. J., \& Langenfeld, M. E. (1999). Influence of music on Wingate anaerobic test performance. Perceptual and Motor Skills, 88, 292-296. http://dx.doi.org/10.2466/pms.1999.88.1.292

Radák, Z. (2018). The physiology of physical training. Cambridge, MA: Academic Press.

Radford, N. B., DeFina, L. F., Leonard, D., Barlow, C. E., Willis, B. L., Gibbons, L. W., . . Levine, B. D. (2018). Cardiorespiratory fitness, coronary artery calcium and cardiovascular disease events in a cohort of generally healthy, middle aged men: Results from the Cooper Center Longitudinal Study. Circulation, 137, 1888-1895. http://dx.doi.org/10 .1161/CIRCULATIONAHA.117.032708 
*RamezanPour, M. R., Moghaddam, A., \& Sadifar, E. (2012). Comparison of the effects of listening to three types of music during exercise on heart rate, blood pressure, rating of perceived exertion and fatigue onset time. Iranian Journal of Health and Physical Activity, 3, 15-20. Retrieved from http://jm.um.ac.ir/index.php/IJHPA

*Ramji, R., Aasa, U., Paulin, J., \& Madison, G. (2016). Musical information increases physical performance for synchronous but not asynchronous running. Psychology of Music, 44, 984-995. http://dx.doi.org/10 $1177 / 0305735615603239$

*Rao, N. S. V. M. P., \& Kumar, J. V. (2015). Role of perceptual factors on endurance profiles on treadmill exercise. Journal of Clinical and Diagnostic Research, 9, CC13-CC15. http://dx.doi.org/10.7860/JCDR/2015/ 12359.6063

Rauscher, F. H., Shaw, G. L., \& Ky, K. N. (1993). Music and spatial task performance. Nature, 365, 611. http://dx.doi.org/10.1038/365611a0

Razon, S., Basevitch, I., Land, W., Thompson, B., \& Tenenbaum, G. (2009). Perception of exertion and attention allocation as a function of visual and auditory conditions. Psychology of Sport and Exercise, 10, 636-643. http://dx.doi.org/10.1016/j.psychsport.2009.03.007

"Rebold, M. J., Lepp, A., Sanders, G. J., \& Barkley, J. E. (2015). The impact of cell phone use on the intensity and liking of a bout of treadmill exercise. PLOS ONE, 10, e0125029. http://dx.doi.org/10.1371/journal .pone.0125029

Rejeski, W. J. (1985). Perceived exertion. An active or passive process? Journal of Sport Psychology, 7, 371-378. http://dx.doi.org/10.1123/jsp .7.4.371

*Rendi, M., Szabo, A., \& Szabo, T. (2008). Performance enhancement with music in rowing sprint. The Sport Psychologist, 22, 175-182. http://dx .doi.org/10.1123/tsp.22.2.175

*Reychler, G., Fabre, J., Lux, A., Caty, G., Pieters, T., \& Liistrol, G. (2017). Influence of different kinds of music on walking in children. Rehabilitation Nursing, 42, 33-38.

*Rhea, C., Butcher-Mokha, M., \& Ludwig, K. (2004). Influence of uptempo music on arousal and selected biomechanics during a near maximum bench press [Abstract]. Research Quarterly for Exercise and Sport, 75, SA2-SA3. Retrieved from http://www.tandfonline.com/toc/ urqe20/current\#.VNS3yy7QDR9

Romero, A. J. (2012). A pilot test of the Latin active hip hop intervention to increase physical activity among low-income Mexican-American adolescents. American Journal of Health Promotion, 26, 208-211. http://dx.doi.org/10.4278/ajhp.090123-ARB-24

Rose, E. A., \& Parfitt, G. (2010). Pleasant for some and unpleasant for others: A protocol analysis of the cognitive factors that influence affective responses to exercise. International Journal of Behavioral Nutrition and Physical Activity, 7, e15. http://dx.doi.org/10.1186/1479-5868-7-15

Rosenthal, R., \& DiMatteo, M. R. (2001). Meta-analysis: Recent developments in quantitative methods for literature reviews. Annual Review of Psychology, 52, 59-82. http://dx.doi.org/10.1146/annurev.psych.52 .1 .59

"Ruscello, B., D’Ottavio, S., Padua, E., Tonelli, C., \& Pantanella, L. (2014). The influence of music on exercise in a group of sedentary elderly women: An important tool to help the elderly to stay active. The Journal of Sports Medicine and Physical Fitness, 54, 536-544. http:// www.ncbi.nlm.nih.gov/pubmed/25034556

Russell, J. A., \& Barrett, L. F. (1999). Core affect, prototypical emotional episodes, and other things called emotion: Dissecting the elephant. Journal of Personality and Social Psychology, 76, 805-819. http://dx .doi.org/10.1037/0022-3514.76.5.805

Ryan, R. M., \& Deci, E. L. (2000). Self-determination theory and the facilitation of intrinsic motivation, social development, and well-being. American Psychologist, 55, 68-78. http://dx.doi.org/10.1037/0003066X.55.1.68
Ryan, R. M., \& Deci, E. L. (2017). Self-determination theory: Basic psychological needs in motivation, development, and wellness. New York, NY: Guilford Press.

*Sanchez, X., Grundy, V. J., \& Jones, M. A. (2005). The effect of music on emotions during sub-maximal exercise [Abstract]. Journal of Sports Sciences, 23, 158-159.

"Sanchez, X., Moss, S. L., Twist, C., \& Karageorghis, C. I. (2014). On the role of lyrics in the music-exercise performance relationship. Psychology of Sport and Exercise, 15, 132-138. http://dx.doi.org/10.1016/j .psychsport.2013.10.007

*Savitha, D., Sejil, T. V., Rao, S., Roshan, C. J., \& Roshan, C. J. (2013). The effect of vocal and instrumental music on cardio respiratory variables, energy expenditure and exertion levels during sub maximal treadmill exercise. Indian Journal of Physiology and Pharmacology, 57, 159-168. http://www.ijpp.com/

Saxena, S., Van Ommeren, M., Tang, K. C., \& Armstrong, T. P. (2005). Mental health benefits of physical activity. Journal of Mental Health, 14 445-451. http://dx.doi.org/10.1080/09638230500270776

Scherer, K. R. (1999). Appraisal theories. In T. Dalgleish \& M. Power (Eds.), Handbook of cognition and emotion (pp. 637-663). Chichester, UK: Wiley.

Scherer, K. R., \& Zentner, M. R. (2001). Emotional effects of music: Production rules. In P. Juslin \& J. A. Sloboda (Eds.), Music and emotion: Theory and research (pp. 361-392). Oxford, UK: Oxford University Press.

*Schie, N. A., Stewart, A., Becker, P., \& Rogers, G. G. (2008). Effect of music on submaximal cycling. South African Journal of Sports Medicine, 20, 28-31. http://dx.doi.org/10.17159/2078-516X/2008/v20i1a291

"Schmid, D. B., Siegel, N. M., \& Deitrick, R. W. (2008). Effects of music on physiological and perceived exertion responses to varying exercise modes [Abstract]. Medicine \& Science in Sports \& Exercise, 40, S264 http://dx.doi.org/10.1249/01.mss.0000322440.16884.c8

Schmidt-Kassow, M., Heinemann, L. V., Abel, C., \& Kaiser, J. (2013). Auditory-motor synchronization facilitates attention allocation. NeuroImage, 82, 101-106. http://dx.doi.org/10.1016/j.neuroimage.2013.05 .111

Schneider, S., Askew, C. D., Abel, T., \& Strüder, H. K. (2010). Exercise, music, and the brain: Is there a central pattern generator? Journal of Sports Sciences, 28, 1337-1343. http://dx.doi.org/10.1080/02640414 .2010 .507252

Sedlmeier, P., Eberth, J., Schwarz, M., Zimmermann, D., Haarig, F., Jaeger, S., \& Kunze, S. (2012). The psychological effects of meditation A meta-analysis. Psychological Bulletin, 138, 1139-1171. http://dx.doi .org/10.1037/a0028168

Shaughnessy, J. J., Zechmeister, E. B., \& Zechmeister, J. S. (2006). Research methods in psychology (7th ed.). Boston, MA: McGraw-Hill.

"Shaulov, N., \& Lufi, D. (2009). Music and light during indoor cycling. Perceptual and Motor Skills, 108, 597-607. http://dx.doi.org/10.2466/ pms.108.2.597-607

Sherman, J., \& Richmond, S. (2013). Listening to music prior to anaerobic exercise improves performance. Journal of Athletic Medicine, 1, 66-69. Retrieved from http://www.jampub.com/index.php/JAM

*Simpson, S. D., \& Karageorghis, C. I. (2006). The effects of synchronous music on 400-m sprint performance. Journal of Sports Sciences, 24, 1095-1102. http://dx.doi.org/10.1080/02640410500432789

Sleight, P. (2013). Cardiovascular effects of music by entraining cardiovascular autonomic rhythms music therapy update: Tailored to each person, or does one size fit all? Netherlands Heart Journal: Monthly Journal of the Netherlands Society of Cardiology and the Netherlands Heart Foundation, 21, 99-100. http://dx.doi.org/10.1007/s12471-0120359-6

Smirmaul, B. P. C. (2017). Effect of pre-task music on sports or exercise performance. The Journal of Sports Medicine and Physical Fitness, 57, 976-984. 
*Smirmaul, B. P. C., Dos Santos, R. V., \& Da Silva Neto, L. V. (2015). Pre-task music improves swimming performance. The Journal of Sports Medicine and Physical Fitness, 55, 1445-1451.

"Soltani, P., \& Salesi, M. (2013). Effects of exergame and music on acute exercise responses to graded treadmill running. Games for Health Journal, 2, 75-80. http://dx.doi.org/10.1089/g4h.2012.0077

Steinbach, P. (2008). Rocking the house. Athletic Business, 8, 66-69. Retrieved from http://www.athleticbusiness.com/

Steptoe, A., \& Bolton, J. (1988). The short-term influence of high and low intensity physical exercise on mood. Psychology \& Health, 2, 91-106. http://dx.doi.org/10.1080/08870448808400346

Sterling, T. D., Rosenbaum, W. L., \& Weinkam, J. J. (1995). Publication decisions revisited: The effect of the outcome of statistical tests on the decision to publish and vice versa. The American Statistician, 49, $108-112$.

Sterne, J. A. C., \& Egger, M. (2001). Funnel plots for detecting bias in meta-analysis: Guidelines on choice of axis. Journal of Clinical Epidemiology, 54, 1046-1055. http://dx.doi.org/10.1016/S0895-4356(01) 00377-8

Sterne, J. A. C., \& Harbord, R. M. (2004). Funnel plots in meta-analysis. The Stata Journal, 4, 127-141. http://dx.doi.org/10.1177/15368 67X0400400204

Sterne, J. A. C., Sutton, A. J., Ioannidis, J. P. A., Terrin, N., Jones, D. R., Lau, J., . . . Higgins, J. P. T. (2011). Recommendations for examining and interpreting funnel plot asymmetry in meta-analyses of randomised controlled trials. British Medical Journal, 343, d4002. http://dx.doi.org/ 10.1136/bmj.d4002

Stork, M. J., Karageorghis, C. I., \& Martin Ginis, K. A. (2019). Let's go: Psychological, psychophysical, and physiological effects of music during sprint interval exercise. Psychology of Sport and Exercise, 45, 101547. http://dx.doi.org/10.1016/j.psychsport.2019.101547

*Stork, M. J., Kwan, M. Y., Gibala, M. J., \& Martin Ginis, K. A. (2015). Music enhances performance and perceived enjoyment of sprint interval exercise. Medicine \& Science in Sports \& Exercise, 47, 1052-1060. http://dx.doi.org/10.1249/MSS.0000000000000494

*Szabo, A., Small, A., \& Leigh, M. (1999). The effects of slow- and fast-rhythm classical music on progressive cycling to voluntary physical exhaustion. The Journal of Sports Medicine and Physical Fitness, 39, 220-225. Retrieved from http://www.minervamedica.it/en/journals/ sports-med-physical-fitness/index.php

*Szmedra, L., \& Bacharach, D. W. (1998). Effect of music on perceived exertion, plasma lactate, norepinephrine and cardiovascular hemodynamics during treadmill running. International Journal of Sports Medicine, 19, 32-37. http://dx.doi.org/10.1055/s-2007-971876

Tabachnick, B. G., \& Fidell, L. S. (2018). Using multivariate statistics (7th ed.). Boston, MA: Pearson.

Tan, F., Tengah, A., Nee, L. Y., \& Fredericks, S. (2014). A study of the effect of relaxing music on heart rate recovery after exercise among healthy students. Complementary Therapies in Clinical Practice, 20, 114-117. http://dx.doi.org/10.1016/j.ctcp.2014.01.001

Tate, A. R., Gennings, C., Hoffman, R. A., Strittmatter, A. P., \& Retchin, S. M. (2012). Effects of bone-conducted music on swimming performance. Journal of Strength and Conditioning Research, 26, 982-988. http://dx.doi.org/10.1519/JSC.0b013e31822dcdaf

Tenenbaum, G. (2001). A social-cognitive perspective of perceived exertion and exertion tolerance. In R. N. Singer, H. A. Hausenblas, \& C. Janelle (Eds.), Handbook of sport psychology (pp. 810-822). New York, NY: Wiley.

Tenenbaum, G., Lidor, R., Lavyan, N., Morrow, K., Tonnel, S., Gershgoren, A., . . J Johnson, M. (2004). The effect of music type on running perseverance and coping with effort sensations. Psychology of Sport and Exercise, 5, 89-109. http://dx.doi.org/10.1016/S1469-0292(02)00041-9

Terry, P. C., \& Karageorghis, C. I. (2006). Psychophysical effects of music in sport and exercise: An update on theory, research and application. In
M. Katsikitis (Ed.), Psychology bridging the Tasman: Science, culture and practice - Proceedings of the 2006 Joint Conference of the Australian Psychological Society and the New Zealand Psychological Society (pp. 415-419). Melbourne, Australia: Australian Psychological Society. Retrieved from http://eprints.usq.edu.au/4364/

Terry, P. C., \& Karageorghis, C. I. (2011). Music in sport and exercise. In T. Morris \& P. C. Terry (Eds.), The new sport and exercise psychology companion (pp. 359-380). Morgantown, WV: Fitness Information Technology.

*Terry, P. C., Karageorghis, C. I., Saha, A. M., \& D'Auria, S. (2012). Effects of synchronous music on treadmill running among elite triathletes. Journal of Science and Medicine in Sport, 15, 52-57. http://dx.doi .org/10.1016/j.jsams.2011.06.003

*Terry, P. C., Mecozzi Saha, A., \& Bool, R. (2012). Effects of synchronous music on elite athletes during training activities [Abstract]. Journal of Science and Medicine in Sport, 15, S251. http://dx.doi.org/10.1016/j .jsams.2011.06.003

*Thakare, A. E., Mehrotra, R., \& Singh, A. (2017). Effect of music tempo on exercise performance and heart rate among young adults. International Journal of Physiology, Pathophysiology and Pharmacology, 9, 35-39. Retrieved from https://www.ncbi.nlm.nih.gov/pmc/articles/ PMC5435671/

"Thakur, A. M., \& Yardi, S. S. (2013). Effect of different types of music on exercise performance in normal individuals. Indian Journal of Physiological and Pharmacology, 57, 448-451. Retrieved from https://www .ncbi.nlm.nih.gov/pubmed/24968586

Thaut, M. H. (2008). Rhythm, music and the brain: Scientific foundations and clinical applications. New York, NY: Routledge.

*Tran, T. T., Biagini, M. S., Brown, L. E., Coburn, J. W., Judelson, D. A., Statler, T. A., . . Bottaro, M. (2011). Effects of self-selected music on vertical jump and squat height [Abstract]. Journal of Strength and Conditioning Research, 26, S101.

Tubino, M. J. G., de Souza, B. C., \& Valladão, R. (2009). An analysis about the contents of the officials and popular anthems of the main soccer teams of the city of Rio de Janeiro from the Primeira República to the Estado Novo. Fitness \& Performance Journal, 8, 56-67.

Turner, E. (2012). Communitas: The anthropology of collective joy. New York, NY: Palgrave Macmillan. http://dx.doi.org/10.1057/ 9781137016423

Van Dyck, E. (2019). Musical intensity applied in the sports and exercise domain: An effective strategy to boost performance? Frontiers in Psychology, 10, e1145. http://dx.doi.org/10.3389/fpsyg.2019.01145

Van Dyck, E., Moens, B., Buhmann, J., Demey, M., Coorevits, E., Dalla Bella, S., \& Leman, M. (2015). Spontaneous entrainment of running cadence to music tempo. Sports Medicine - Open, 1, 15. http://dx.do .org/10.1186/s40798-015-0025-9

van Sluijs, E. M. F., McMinn, A. M., \& Griffin, S. J. (2007). Effectiveness of interventions to promote physical activity in children and adolescents: Systematic review of controlled trials. British Medical Journal, 335, e703. http://dx.doi.org/10.1136/bmj.39320.843947.BE

Viechtbauer, W. (2010). Conducting meta-analyses in R with the metafor package. Journal of Statistical Software, 36, 1-48. http://dx.doi.org/10 .18637/jss.v036.i03

Wanner, M., Richard, A., Martin, B., Faeh, D., \& Rohrmann, S. (2017). Associations between self-reported and objectively measured physical activity, sedentary behavior and overweight/obesity in NHANES 20032006. International Journal of Obesity, 41, 186-193. http://dx.doi.org/ 10.1038/ijo.2016.168

Webb, T. L., Miles, E., \& Sheeran, P. (2012). Dealing with feeling: A meta-analysis of the effectiveness of strategies derived from the process model of emotion regulation. Psychological Bulletin, 138, 775-808. http://dx.doi.org/10.1037/a0027600

"White, V. B., \& Potteiger, J. A. (1996). Comparison of passive sensory stimulations on RPE during moderate intensity exercise. Perceptual and 
Motor Skills, 82, 819-825. http://dx.doi.org/10.2466/pms.1996.82.3 .819

Will, U., \& Berg, E. (2007). Brain wave synchronization and entrainment to periodic acoustic stimuli. Neuroscience Letters, 424, 55-60. http:// dx.doi.org/10.1016/j.neulet.2007.07.036

Williams, D. M. (2008). Exercise, affect, and adherence: An integrated model and a case for self-paced exercise. Journal of Sport \& Exercise Psychology, 30, 471-496. http://dx.doi.org/10.1123/jsep.30.5.471

Williams, D. M., Dunsiger, S., Jennings, E. G., \& Marcus, B. H. (2012). Does affective valence during and immediately following a 10-min walk predict concurrent and future physical activity? Annals of Behavioral Medicine, 44, 43-51. http://dx.doi.org/10.1007/s12160-012-9362-9

Williams, D. M., Rhodes, R. E., \& Conner, M. T. (Eds.). (2018). Overview of affective determinants of health behavior. Affective determinants of health behaviour (pp. 1-18). New York, NY: Oxford University Press. http://dx.doi.org/10.1093/oso/9780190499037.003.0001

*Yamashita, S., Iwai, K., Akimoto, T., Sugawara, J., \& Kono, I. (2006). Effects of music during exercise on RPE, heart rate and the autonomic nervous system. The Journal of Sports Medicine and Physical Fitness,
46, 425-430. Retrieved from http://www.minervamedica.it/en/journals/ sports-med-physical-fitness/index.php

*Young, S. C., Sands, C. D., \& Jung, A. P. (2009). Effect of music in female college soccer players during maximal treadmill test. International Journal of Fitness, 2, 31-36. Retrieved from https://www.iat.unileipzig.de/datenbanken/iks/nwls/Record/4016456

Zhang, J. M., Wang, P., Yao, J. X., Zhao, L., Davis, M. P., Walsh, D., \& Yue, G. H. (2012). Music interventions for psychological and physical outcomes in cancer: A systematic review and meta-analysis. Supportive Care in Cancer, 20, 3043-3053. http://dx.doi.org/10.1007/s00520-0121606-5

Ziv, G., \& Lidor, R. (2011). Music, exercise performance, and adherence in clinical populations and the elderly: A review. Journal of Clinical Sport Psychology, 5, 1-23. http://dx.doi.org/10.1123/jcsp.5.1.1

Received October 19, 2015 Revision received September 23, 2019 Accepted October 1, 2019

\section{E-Mail Notification of Your Latest Issue Online!}

Would you like to know when the next issue of your favorite APA journal will be available online? This service is now available to you. Sign up at https://my.apa.org/portal/alerts/ and you will be notified by e-mail when issues of interest to you become available! 